\title{
A Network Model of Financial System Resilience
}

\author{
Kartik Anand* \\ Prasanna Gai** \\ Sujit Kapadia*** \\ Simon Brennan*** \\ Matthew Willison***
}

$\frac{v}{\alpha}$

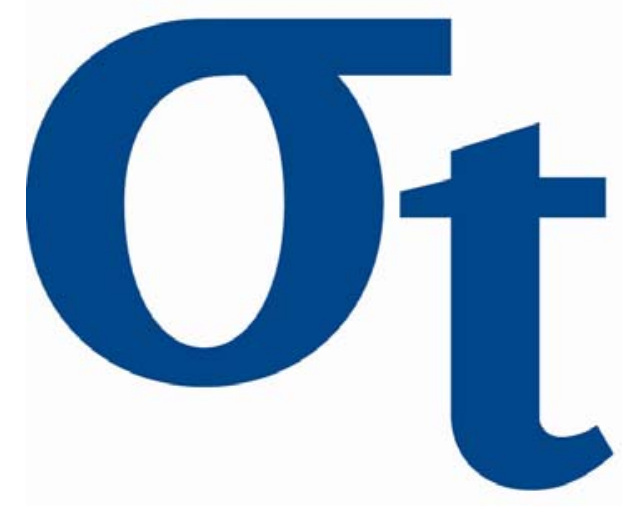

* Technische Universität Berlin, Germany $* *$ University of Auckland, New Zealand $* * *$ Bank of England, UK

This research was supported by the Deutsche Forschungsgemeinschaft through the SFB 649 "Economic Risk". 


\title{
A Network Model of Financial System Resilience
}

\author{
Kartik Anand ${ }^{* a}$, Prasanna Gai ${ }^{\mathrm{b}}$, Sujit Kapadia ${ }^{\mathrm{c}}$, Simon Brennan ${ }^{\mathrm{c}}$, Matthew \\ Willison ${ }^{\mathrm{c}}$ \\ ${ }^{a}$ Technische Universität Berlin, Sek. H 52, Straße des 17. Juni 135, 10623 Berlin, Germany \\ ${ }^{b}$ Department of Economics, University of Auckland, 12 Grafton Road, Auckland 1142, New Zealand \\ ${ }^{c}$ Bank of England, Threadneedle Street, London EC2R 8AH, UK
}

\begin{abstract}
We examine the role of macroeconomic fluctuations, asset market liquidity, and network structure in determining contagion and aggregate losses in a financial system. Systemic instability is explored in a financial network comprising three distinct, but interconnected, sets of agents - domestic banks, international financial institutions, and firms. Calibrating the model to advanced country banking sector data, we obtain sensible aggregate loss distributions which are bimodal in nature. We demonstrate how systemic crises may occur and analyze how our results are influenced by firesale externalities and the feedback effects from curtailed lending in the macroeconomy. We also illustrate the resilience of our model financial system to stress scenarios with sharply rising corporate default rates and falling asset prices.
\end{abstract}

JEL classification: C63, G01, G17, G21.

Key words: Contagion, Financial crises, Network models, Systemic risk. 


\section{Introduction}

The complex and opaque nature of modern financial systems poses a considerable challenge for the analysis of systemic resilience. An intricate web of claims and obligations links households and firms to a wide variety of financial intermediaries such as banks, insurance companies, and hedge funds. The rapid development of securitization and credit derivative markets has also made exposures between agents difficult to assess and monitor. The global financial crisis of 2007-8 illustrates how intertwined the financial network has become, whilst also making clear the potential for widespread losses and instability.

Recent efforts by central banks to measure and assess systemic risk have emphasized the important role played by network effects, firesale externalities, and funding liquidity risk in financial stability. ${ }^{1}$ A general insight, highlighted by Alessandri et.al (2009), is that these factors generate "fat tails" in the distribution of aggregate losses for the banking system. This is consistent with recent analytical work which suggests that financial systems, like other complex networks, have "tipping points", display a "robust-yet-fragile" tendency - with sharp discontinuities emerging following some unexpected shocks, with other shocks resulting in benign effects (May et.al. (2008); May and Haldane (2011); Gai and Kapadia (2010); Gai et.al (2011)).

\footnotetext{
${ }^{2}$ An earlier version of this paper was circulated under the title, Complexity and Crises in Financial Systems. We are grateful to David Aikman, Dilek Bülbül, Andy Haldane, Simon Hall, Reimer Kühn, Myron Kwast, Paul Ormerod, Joe Pearlman, Gabriel Sterne and Martin Summer for helpful comments and suggestions for improvement. The comments of participants at the GRETA Associati CREDIT 2009 conference on Credit Risk, Financial Crises, and the Macroeconomy (Venice, 24-25 September, 2008), the Royal Economic Society Annual Conference (Guildford, 20-22 April 2009), the Money, Macro and Finance Research Group Conference on "Financial Stability and Transmission of Credit Risk" (London, 21 May 2009), the Bank for International Settlements workshop on Challenges in Banking Research (Basel, 28-29 May, 2009), the Econometric Society European Congress (Barcelona, 23-27 August, 2009), The European Central Bank workshop on Recent Advances in Modelling Systemic Risk Using Network Analysis (Frankfurt am Main, 5 October, 2009), the Conference on Post-Crisis Financial Sector Performance (Bangor, 23 June 2011) and seminar participants at the Bank of England are also gratefully acknowledged.

This paper represents the views of the authors and should not be thought to represent those of the Bank of England, its Monetary Policy Committee, or its Financial Policy Committee members.

${ }^{*}$ Corresponding author; kartik.anand@tu-berlin.de. KA acknowledges support of the Deutsche Forschungsgemeinschaft through the Collaborative Research Center (Sonderforschungsbereich) SFB 649 on "Economic Risks".

${ }^{1}$ See, for example, Elsinger et.al (2006) for the Austrian banking system, Aikman et.al (2009) for the UK, and Gauthier et.al (2010) for Canada. Foglia (2009) provides a detailed overview of systemic risk assessment models being developed by central banks. Cifuentes et.al (2005) and Morris and Shin (2009) offer analytical accounts of firesale effects and funding liquidity risk.
} 
These central bank studies rely on highly detailed, and relatively static, balance sheet data to establish precise linkages between banks in the domestic financial system and to derive banking system losses. As such, their usefulness is constrained when true linkages are not known (such as with credit risk transfer or off-balance sheet activity) or when shocks strike financial players external to the core banking system. The pre-defined balance sheet interlinkages in these models also precludes analysis of how network structure matters for system resilience. The crisis has emphasized how network linkages and interactions between banks are critical to understanding systemic risk. And the growing importance of "stress testing" exercises in the policy debate about financial stability points to the need for analyses that help overcome such limitations.

In this paper, we set out a general framework to gauge systemic risk in circumstances when data about the reach of financial exposures is limited and shocks are international in nature. We present a statistical model of a financial system involving a diverse set of financial agents, namely domestic banks, domestic firms, and international financial institutions. We calibrate the model to advanced country banking sector data to illustrate how macroeconomic fluctuations, asset market liquidity and network structure interact to determine aggregate credit losses and contagion. Although the calibration is deliberately broad-brush so as to emphasize the qualitative nature of the results, we obtain plausible fat-tailed (bi-modal) aggregate loss distributions and can quantify the size of the macroeconomic or financial sector shock that may be necessary for system-wide failure to occur.

The model highlights how shocks are propagated through the direct interlinkages of claims and obligations amongst (and between) domestic banks and international financial institutions. But it also shows how defaults across the network are amplified by asset fire sales and curtailed lending in the macroeconomy as credit crunch effects take hold in the event of distress. In addition, we illustrate how greater heterogeneity of bank balance sheets leads to more realistic outcomes, characterized by the failure of some - but not all - banks in extreme scenarios.

We also demonstrate how the model can be used to "stress-test" the banking system. We draw on some recent bank stress testing exercises to examine the consequences for bank failure in our model. The results obtained are entirely illustrative and intended to demonstrate the usefulness of the framework. Specifically, we consider a scenario in which the loss rate on corporate exposures of around $4.5 \%$ and is accompanied by a $20 \%$ fall in equity prices as a result of firesales. Faced with such stress, approximately one quarter of our model banking system is pushed into default. Our findings do not seem implausible given that we explicitly take into account macroeconomic and fire sale effects, although the assumption of $100 \%$ loss-given-default (LGD) suggests this estimate sets an upper bound on bank failures. 
Our analysis complements recent work that draws on techniques from network science and statistical physics to study credit contagion and model credit risk losses in banks' portfolios (Giesecke and Weber (2004, 2006); Horst (2007); Hatchett and Kühn (2009); Gai and Kapadia (2010); May and Arinaminpathy (2010)). But the networks in these models typically involve homogeneous agents - a firm or a bank - and do not capture the twin effects of macroeconomic and firesale feedbacks.

Our analysis also relates to the literature which seeks to obtain analytical valuation results for complex portfolio credit derivatives by considering default correlation and credit contagion among firms in a dynamic setting Errais et.al (2010); Longstaff and Rajan (2008). In contrast to these papers, clearly specified bank balance sheets are central to our approach, with bilateral linkages precisely defined with reference to these. And our differing modelling strategy, which focuses on the transmission of contagion along these links, reflects the greater structure embedded in our network set-up.

In choosing to model the complexity of a heterogeneous financial system with feedback effects, we have allowed relatively little role for behavior. Analytical tractability precludes optimizing agents and strategic interactions. Although we allow for plausible "rules of thumb" that permit banks to curtail lending and dispose assets in a firesale, the contagion process is mechanistic. The size and structure of financial linkages is kept constant as default cascades develop. While this assumption may be defensible in the midst of a rapidly developing crisis, it is clearly at odds with recent work on financial networks (Leitner (2005); Castiglionesi and Navarro (2007)) that builds upon the seminal contribution of Allen and Gale $(2000)^{2}$. The stylized nature of these models means, however, that they cannot be used for systemic risk assessment. So our paper should be viewed as a very preliminary first step towards an integrated model of systemic risk that both takes complexity seriously and incorporates realistic behavioral responses.

The paper proceeds as follows. Section 2 provides an informal discussion of our approach and explains how shocks are propagated and amplified in a stylized financial system comprising diverse agents. Section 3 describes model calibration and discusses a novel approach to deriving the distributions of balance sheet exposures in environments when data is unavailable. Section 4 presents the baseline aggregate loss distribution obtained from stochastic simulations and considers how liquidity risk and macroeconomic feedbacks might affect system stability. Section 5 presents an example of how the model can be used for a banking system stress

\footnotetext{
${ }^{2}$ See Allen and Babus (2008) for a survey of network-theoretic approaches to modelling financial issues. Jackson (2008) provides detailed discussion of strategic behavior on networks.
} 
test. A final section concludes. Formal details of the model and a description of how distributions of exposures are obtained from maximum entropy techniques are presented in the appendices.

\section{A stylized financial system and the transmission of shocks}

The financial system in our model can be viewed as a core-periphery structure with three inter-connected layers - domestic banks, international banks and firms. While we do not model lending to households in this structure, the framework could easily be augmented to include a role for them in a similar way to the treatment of firm.

A network of core domestic banks sits at the center of the system. A distinguishing feature of this group is that each bank interacts with all other banks, i.e., the (sub-) network of domestic banks is complete. This structure reflects the importance of core banks within money markets and payment systems in national financial structures ${ }^{3}$.

Beyond this group of core banks lies a group of international banks, i.e., banks operating in foreign countries and peripheral to the core domestic financial system. Unlike domestic banks, the (sub-) network of international banks is incomplete and exhibits a 'small world' property - each international bank interacts with institutions in its immediate vicinity and only interacts with more distant institutions with some probability. The sparseness of the links between international banks relative to the complete network of domestic banks reflects the much greater diversity of institutions in this sector, both in terms of activity and location. It is also consistent with recent evidence from von Peter (2007) on the financial linkages between international banking centers.

The outer-most layer of the financial system is comprised of firms in the economy. Firms are assumed not to lend to each other and do not own shares in one another. They are, thus, not connected to each other in any way. This assumption is made for tractability. Firms are, however, assigned an exogenous credit rating (investment or speculative grade), are subject to common aggregate economy-wide shocks, and exposed to the risk of restrictions in bank credit. The performance of different firms across the economy is therefore correlated following a shock to the financial system.

Although the three layers of the financial system are distinct, each group is linked to the others. Domestic and international banks can lend to, and borrow from, each other. They are also able to lend to, and own shares (direct investments)

\footnotetext{
${ }^{3}$ Our data on lending between domestic UK banks corroborates this assumptions.
} 
in, firms. The financial relationships across layers are modelled as random graphs. In other words, entities belonging to different layers are linked to each other with a given probability. These probabilities are independent between pairs of entities, and the random links mean banks can differ in terms of lending to, and equity holdings in, firms.

Figure 1 illustrates the financial system. Our use of random graph techniques to model the interlinkages between different types of agent can be viewed as a metaphor for the opacity and reach of modern financial instruments. Policymakers frequently highlight the way in which financial innovation has enabled financial intermediaries to 'slice and dice' credit risks to the peripheries of the financial system (Bank of England (2007a); Trichet (2008)). The value of instruments such as credit derivatives and their related exposures are difficult to monitor as a result, justifying the probabilistic treatment adopted here.

As Figure 1 shows, banks and firms are represented as nodes in a network. Although not illustrated, links between nodes reflect credit or equity relationships and the network is directed, with incoming links representing assets (i.e., monies owed to an entity by a counterparty or shares in the case of banks' relationships with firms) and outgoing links representing liabilities. Figure 2 presents the typical balance sheet of a bank in the financial system. Total assets comprise loans to firms, loans to other banks (domestic and international), shares in firms, and government securities. The liability side of the balance sheet includes customer deposits, interbank borrowing, and the bank's capital buffer. Our balance sheet structure is sufficiently simple to be tractable whilst including enough granularity to be interesting.

Appendix A provides a formal presentation of the model. It specifies banks' balance sheets and shows how our assumptions about connectivity allow the financial system described above to be cast in convenient matrix form. It also specifies how shocks give rise to crisis dynamics and contagion.

An informal sense of the mapping from shocks to systemic risk can, however, be readily gleaned from Figure 3. Macroeconomic disturbances can trigger firm defaults, leading to credit losses and losses on holdings of firm equities at some banks. These shocks can trigger the default of a financial institution and generate a default cascade amongst banks that are directly linked ${ }^{4}$. But as the losses at an individual bank mount, approaching a critical fraction of capital, it is also likely to take defensive action to try to protect itself from failure. Specifically, it is likely to

\footnotetext{
${ }^{4}$ Alternatively, a financial institution may fail for idiosyncratic reasons without there being a macroeconomic shock.
} 
sell assets (equities) once in distress and cut back on its lending to firms ${ }^{5}$. The firesale of equities and resultant asset price decline gives rise to mark-to-market losses, forcing other banks to write down the value of their assets and potentially enter into their own fire sales and tighten their own lending to firms. Meanwhile restrictions in credit increase the probability probability of default of firms, magnifying the initial shock. Direct contagion is, thus, reinforced by firesales and macroeconomic feedback effects.

We strictly assume that the banking sector is the sole provider of credit for firms who do not have direct access to credit markets or any other channel of credit. Our focus and assumption is a stylized attempt to capture macroeconomic feedback loops from the financial system to the real economy. Moreover, one may expect our assumption to be qualitatively true during periods of financial crisis, where due to a confluence of high capital search costs and a hoarding of liquidity by all institutions, i.e., a credit crunch, the probability of default for firms increases, which exacerbates the financial crisis.

In the mechanistic setting adopted here, banks follow rules of thumb when confronted with distress. Although plausible, these rules have no micro-foundations. But they can be viewed as being consistent with rational behavior. Facing a highly uncertain recovery rate and timing of economic recovery in the midst of crisis, banks are likely to assume a worst case scenario and be willing to pull credit lines. For simplicity we do not assume an explicit link between a fall in equity prices and the default probabilities of firms. These channels are subsumed with other behavioral factors that collectively raise the credit risks of firms. If such loans are denied the firm defaults on existing loans to other banks, thereby exacerbating the crisis.

\section{Model calibration}

We attempt to characterize the state of a modern financial system prior to the onset of the global financial crisis. Although we draw upon UK data for much of our calibration, our choice of parameters is intended to be purely illustrative and does not purport to quantify systemic risk in the UK. Our intention, instead, is to showcase how the model can usefully generate plausible measures of systemic risk and clarify the interplay between macro-financial shocks, market liquidity, and network structure within a financial system. Since some of the exposure data

\footnotetext{
${ }^{5}$ Our approach does not model the dynamic restructuring of balance sheets. In other words, the actual transfer of equity from one bank to another as a result of the firesale is absent. We motivate this stylized assumption by qualifying our firesale as an anticipated firesale. Once a bank's capital falls below the critical threshold, all other market participants will anticipate that the bank will perform a firesale in the near future. It is this anticipation that results in the fall of equity prices.
} 
is confidential in nature, we verbally describe how we calibrate some of the key statistics necessary for our maximum entropy procedure. These exposure statistics are, however, reported in detail where the data is publicly available.

The network consists of 17 domestic banks, 240 international banks, and 50,000 firms. Seventeen domestic-owned banks accounted for $95 \%$ of banking assets in the UK at end-2007, while three-quarters of foreign exchange turnover during 2004 was accounted for by some 240 non-UK banks located in 20 countries the Bank for International Settlements (2008) 'Consolidated Banking Statistics Report', which publishes aggregate statistics on cross-border loans and explicitly excludes nonbank financial entities such as insurance agencies and hedge funds. Our choice of the number of firms is based on the UK's Department for Business Innovation and Skills press release on Small and Medium Enterprise Statistics. At the beginning of 2008 they recorded approximately 33,000 firms in the UK with 50 employees or more. Our choice of 50,000 firms is broadly illustrative of this statistic. Clearly, the number of foreign financial institutions and firms can be much larger, so our choice simply indicates the situation facing an economy with a highly developed and integrated financial sector.

Given the paucity of data about exposures between banks internationally, and between domestic firms and international banks, we rely on deriving distributions of exposure sizes and the number of links between the three types of agent from a limited data set. We use quarterly time series data on balance sheets over a four year horizon (2004-2007) to fit least biased distributions. These establish the financial connections of our network. Appendix B shows how empirical constraints observed in the data are accounted for in selecting a least biased distribution that also maximizes information content.

A novel feature of the calibration is our use of the principle of maximum entropy to estimate the distributions of exposures between financial players. Specifically, we use the principle of maximum entropy to approximate the empirical distribution of exposures. The entropy, which is a function of the probability distribution, is a measure of the predictability of exposures. When the entropy is large, there is greater uncertainty on our current state of knowledge and it is harder to predict typical exposure values. In this case, the distribution of exposures is broad. On the other hand, when the entropy is small, the distribution is sharply peaked around a small range of exposures, thereby improving the predictability. The principle of maximum entropy postulates that subject to known constraints (knowledge of the first few moments from the empirical distribution, for example), the probability distribution that best represents our current knowledge and that is least biased is the one with maximal entropy. Importantly, the principle does not require the modeler to make prior assumptions on the shape of the probability distribution. We implement our maximum entropy procedure using the algorithm provided by 
Mohammad-Djafari (1991).

Our approach is distinct from the maximum entropy methods used in central bank analyses (eg Elsinger et.al (2006); Upper (2011)). These studies estimate realizations of exposure matrices whose entropy is as close as possible to a reference matrix. The entropy here is a function of the exposure matrices themselves, which have been suitably re-scaled to satisfy properties of probability distributions.

\subsection{Structure of balance sheets}

We use end-2007 published accounts data for the 17 UK banks and corresponding data for international banks reported in BankScope to characterize the balance sheets used in the model. The average total asset size for UK and international banks are $£ 400$ bn and $£ 150$ bn respectively. For UK banks, equities, loans to firms and interbank assets (the sum of claims against both foreign and other UK banks) made up $10 \%, 80 \%$ and $10 \%$ of assets respectively, on average. The data from Bankscope suggest a similar picture for international banks' balance sheets, so we adopt the same composition for these balance sheets as well.

\subsection{Distribution of exposure sizes between banks}

We calibrate the distribution of interbank loans between domestic (UK) banks using confidential quarterly data on regulatory large exposures for the 17 major banks between 2004-2007. The empirical mean, standard deviation and skewness for the bilateral claims between UK banks were calculated and form the constraints in calculating the maximum entropy PDF. Figure 4 plots the maximum entropy PDF (solid line) against actual data (circles) on a Y-logarithmic scale. ${ }^{6}$ For comparison, we also plot a fitted log normal distribution (dashed line). Both the maximum entropy and log-normal distributions fit the empirical distribution fairly well.

To establish the distribution of loan sizes between domestic and international banks, we suppose that the 240 banks originate from the 20 most financially advanced countries for which data is readily available in the Bank for International Settlements (2008), 'Consolidated Banking Statistics Report'. We use this information to establish the sterling claims of UK banks on other countries' banking systems and vice versa. We assume that all international banking claims are channeled through the 17 core domestic banks and the 8 international banks in each foreign country. We approximate the individual bank-to-bank claims by dividing the aggregated claims of all domestic banks by the number of UK banks (17) and the number of international banks per country (12).

\footnotetext{
${ }^{6}$ The PDF for the actual data was obtained by binning the bilateral exposures and normalizing the weight attributed to each bin. The circles in Figure 4 correspond to bin centers.
} 
Empirical means, standard deviations and skewness statistics were also calculated for claims held by UK banks against international banks. For those held by international banks against UK banks, the mean, standard deviation and skewness were $£ 0.28 \mathrm{bn}, £ 0.67 \mathrm{bn}$, and 4.56 . Figure 4 plots the maximum entropy and fitted log-normal PDFs of loans sizes between international and domestic banks. There is again reasonable agreement between the actual and fitted PDFs, although the maximum-entropy PDF seems to capture the fat tailed nature of the distribution somewhat better.

The international banks in our system, of course, also lend to each other as well as to banks within their own jurisdictions. Data on interbank lending within foreign banking systems is not available, however. So we suppose that each international bank lends to ten of its local counter-parties ${ }^{7}$ and that lending between these banks follows the same statistics as interbank lending within the UK.

In order to calibrate the distribution of exposure sizes between international banks in different countries, we make use of cross-border claims data from the BIS. The mean, standard deviation, and skewness of each exposure is $£ 0.25 \mathrm{bn}, £$ $0.81 \mathrm{bn}$, and 6.84 respectively. The fitted maximum entropy distribution in Figure 4 provides a reasonable description of the data, including the fatness in the tail.

\subsection{Connections between banks}

In addition to exposure sizes, we also need to establish the number of links between banks to construct the financial network. To obtain the maximum entropy distribution for the number of links that a bank has against other banks, we use the results of Bianconi (2009) that for uncorrelated networks, the maximum entropy distribution for the number of links is a Poisson distribution. Uncorrelated networks are those where the degrees of nodes are not correlated. To argue that our financial network may be modeled by an uncorrelated network we assume that domestic banks are owned by domestic shareholders only. If, on the other hand, domestic banks were owned by international shareholders, this would lead to bias in the structure of links between domestic and foreign banks. This assumption holds for our selection of core UK banks. And since we do not know the identities of the other international banks, our assumption serves as a null hypothesis for the structure of linkages.

To construct this distribution for our financial system, we need the average number of links between agents - banks or firms - of type $\mathrm{X}$ against those of type $\mathrm{Y}$, denoted $\left\langle c^{X Y}\right\rangle$. This implies that the probability that any link is present between

\footnotetext{
${ }^{7}$ As made clear below, to utilize the 'small-world' network algorithm of Watts and Strogatz (1998) the number of local counter-parts for each international bank must be even.
} 
two banks is $p^{X Y}=\frac{\left\langle c^{X Y}\right\rangle}{N^{Y}}$, where $N^{Y}$ is the total number of banks of type Y. So the problem reduces to estimating the average number of links between the various types of banks.

We take the domestic banking network as being completely connected. The average number of connections for claims held by domestic banks against international banks is obtained by taking the average total interbank assets of a UK bank, subtracting the average total assets held against other UK banks, and dividing by the average size of an exposure between a UK and international bank. This suggests that each domestic (UK) bank is exposed to 52 international banks.

To establish connections between international banks, we assume that each international bank is connected, on average, to 4 domestic UK banks. In this case, the fraction of domestic UK banks each foreign bank has loans with (4/17) is roughly equal to the fraction of foreign banks each domestic UK bank has loans against (52/240). Each international bank lends to ten other banks in its own country. We model the network of all international banks as a 'small world' network, where each international bank is linked to those in immediate proximity (banks in the same country) and has occasional 'long range' connections to other international banks. The means that the number of 'immediate-neighbor' connections (between international banks in the same country) is $2 \kappa=10$. We obtain the average number of 'long range' connections by taking average total interbank assets $(10 \%$ of $£ 150$ bn), subtracting the average assets held against domestic UK banks $(4 \times £$ $0.28 \mathrm{bn}$ ) and those held against other banks in the same country, and dividing this quantity by the average size of an exposure between international banks in different countries ( $£ 0.25$ bn). This gives approximately 7 'long range' connections. Defining the 'long-range' wiring probability as $p$, the average degree for each node is $2 \kappa(1+p)$, implying that $p=0.7$.

As Figure 5 illustrates, we arrange the nodes of international banks in a ring, connecting each to its immediate (local) neighbors, and then randomly (with probability $p$ ) allowing an international bank to form connections with another bank internationally that is chosen from a uniform distribution over all international banks. This procedure is iterated over all international banks.

\subsection{Distribution of loans to firms and equity holdings}

In the absence of data on individual bank lending to firms, we use our breakdown of banks' balance sheets to suppose that each loan and equity holding is, on average, $£ 100$ mil and $£ 10$ mil, respectively for UK banks and $£ 12$ mil and $£$ 1.2 mil for international banks. The data on average balance sheet size and contributions from loans and equities allows us to infer the connections between domestic (D) and international banks (I) and firms (F). These are $\left\langle c^{D F}\right\rangle=3200$ and $\left\langle c^{I F}\right\rangle=3200$ for loans, and $\left\langle d^{D F}\right\rangle=4000$ and $\left\langle d^{I F}\right\rangle=4000$ for equities. 


\subsection{Corporate default probabilities}

Our calibration of corporate sector default probabilities is based on a study of US investment and speculative grade firms by Schuermann and Hanson (2004). They use credit rating data from Standard and Poors over the period 1981-2002 to establish Gaussian density functions for annual default probabilities in each grade. We base our default probabilities upon these parameterized density functions. Specifically, we treat the default probability in investment (A) grade category as having a mean and standard deviation of $\left\langle P D^{I G}\right\rangle=8.65 \times 10^{-5}$ and $\sigma^{I G}=2 \times 10^{-5}$, respectively. The non-investment grade (BB) category has a mean and standard deviation of $\left\langle P D^{N I G}\right\rangle=6.3 \times 10^{-3}$ and $\sigma^{N I G}=6.1 \times 10^{-4}$, respectively. The proportion of firms that are investment grade (speculative grade) within the system is $0.7(0.3)$. We take the firm LGD to be $35 \%$.

The probabilities of default for all firms are also influenced by an common economy wide shock $\mu_{G}$. The larger $\mu_{G}$, indicating a worsening of the macroeconomic outlook, the higher are the probabilities of default for all firms, irrespective of their rating grade. We do not calibrate $\mu_{G}$, instead we use it as variable in order to explore how large a macroeconomic shock needs to be in order to "tip" the financial system into a systemic crisis.

\subsection{Additional parameters}

Our model also makes use of some additional parameters that are critical in determining the extent of feedback effects following a shock to the financial network. Specifically,

- Ratio of capital to assets (leverage ratio), $\pi$ : we initially set banks' (unweighted) capital buffers to be a uniform $\pi=4 \%$ of total assets, a figure drawn from the 2005 published accounts of a range of large international banks. We then allow capital buffers to vary across banks in the range $[4-24] \%$. In section 4.4, we relax the assumption of uniform capital buffers allowing them to vary in the range $[4-24] \%$.

- Trigger rule for firesales, $\alpha$ : once a banks' losses from the combined effects of corporate defaults, mark to market losses on its equities, and interbank losses amount to $50 \%$ of its initial capital buffer, the bank will decide to put its own tradeable assets up for sale. This trigger level of 50\% amounts to setting the parameter $\alpha=0.5$.

- Liquidity discount parameter, $\lambda$ : we set $\lambda=0.7$ to reflect the fact that once $10 \%$ of equity is put up for sale, the equity price $\mathrm{q}(\mathrm{t})$ will fall by $7 \%$. Our parameterization of the price impact of a firesale is, to a large extent, 
arbitrary since evidence on the price impact of firesales is scarce. Mitchell et.al (2007) analyze firesales of US convertible bonds by hedge funds in 2005 , and suggest that price discounts were around $3 \%$ when some $5 \%$ of the market was sold. This would correspond to a value of $\lambda=0.57$ in our model. Given this estimate is based upon a period of relatively low stress in the financial system, we adopt a value for $\lambda$ consistent with a more significant price impact.

- Macroeconomic feedback parameter, $\psi$ : since macroeconomic feedback effects in the current crisis are yet to be properly calibrated, we (somewhat arbitrarily) set $\phi=6.25 \times 10^{-5}$ as a working hypothesis. This implies, fairly plausibly, that if a bank reduces the volume of credit it issues to firms by $20 \%$ this will increase the probability of default for all firms that have preexisting loans against the bank equally, irrespective of whether the bank is domestic or international. Specifically, we set $\psi=0.2 /\left(\frac{\left\langle c^{D F}\right\rangle+\left\langle c^{I F}\right\rangle}{2}\right)$. Thus, if all banks have more loans, on average, the impact of one bank tightening its' credit conditions is mapped into a smaller rise in the probability of default of firms. The trigger rule for a bank to tighten lending conditions is identical to that for firesales and is governed by the ratio $\alpha$ of losses to the capital buffer.

\section{Credit events, aggregate losses, and feedback effects}

We now present a plausible aggregate loss distribution for the calibrated financial system and evaluate its response to adverse credit shocks. Standard industry models of systemic risk do not consider the complexity implied by international financial linkages and are typically limited in their characterization of the feedback effects from asset firesales and tightening credit conditions in the macroeconomy. The extent to which these factors combine to generate fat tails in the aggregate loss distribution is critical to the assessment of financial system resilience. In what follows, we assume a zero recovery rate on loans. This stark assumption is made for tractability and to highlight our findings, but can be readily relaxed without affecting the spirit of the results. Given both this and the broad-brushed nature of the more general calibration, the results presented below should be taken as purely illustrative rather than as a precise measure of systemic risk in the financial system.

\subsection{The baseline aggregate loss distribution}

We perform a series of stochastic simulations to obtain an aggregate loss distribution under a set of baseline assumptions. Specifically, we assume that asset firesales have no price impact and that there are no macroeconomic feedback effects $(\lambda=\psi=0)$. There are also no aggregate macroeconomic shocks to firms $\left(\mu_{G}=0\right)$. 
For each simulation, we generate balance sheets where exposures are drawn from the connectivity and asset size distributions described in Section 3. Next, through a series of Bernoulli trials, we set some of the firms to default. These defaults are registered on banks' balance sheets, possibly prompting defaults or firesales. Once the shock has run its course through the network and asset prices have adjusted, we measure the fraction of failed banks and the balance sheets of all banks in the system. We perform 1000 such simulations and create a distribution for banking system assets lost.

The inset of Figure 6 presents the normalized histogram for the number of defaulting firms from the initial credit shock. The number of failures from subjecting firms to a shock is characterized by a Bernoulli distribution function (see description in Appendix A.4). The typical defaulting firm is small in relation to the overall financial system - the average size of a defaulting firm is $0.003 \%$ of total system assets. In the baseline, 150 firms default on average in each simulation.

Figure 6 presents the aggregate loss distribution for the banking system, as a fraction of total banking system assets, for the domestic bank network and the overall financial system. The idiosyncratic defaults on the scale described above have very little impact on system resilience - there are no bank defaults. Average system losses as a result of the idiosyncratic shocks are some $0.17 \%$ of the domestic banking system and $0.16 \%$ of the overall system. In other words, both domestic and international banks are similarly affected following idiosyncratic corporate failures.

\subsection{Macroeconomic shocks}

Aggregate macroeconomic shocks to the financial system have an adverse effect on firms and enter the model via the parameter, $\mu_{G}$, the increase of which reflects higher levels of firm default.

We begin by attempting to identify the scale of firm default, absent any feedback effects from firesales or a credit crunch, that triggers the first instances of complete financial system failures (i.e the failure of all domestic and international banks). The results reported for each $\mu_{G}$ are compiled from performing 500 draws of the shock and letting them run their course through the system. The initial instance of system-wide failure occurs at $\mu_{G}^{c}=0.078$. This point is depicted in Figure 7 by a downward facing triangle, and is associated with the default of 2700 firms on average. For $\mu_{G}<\mu_{G}^{c}$, we only observe cases where at most one international bank fails. At $\mu_{G}^{c}$, by contrast, we observe that there are no bank failures $99.5 \%$ of the time, one bank failing $0.1 \%$ of the time, and in the remainder $0.4 \%$ of cases the entire system fails. In these instances of complete network failure, the initial macroeconomic shock reduces the capital buffer for banks holding loans and equity against the defaulting firms, triggering the direct failure of a few banks. Interbank 
linkages then lead to direct contagion, as the similarity among banks in their ability to absorb shocks leads to a starkly bi-polar result in which all banks fail once widespread contagion has broken out. At the critical value $\mu_{G}^{c}$, the loss distribution becomes bimodal for the first time.

Figure 7 also shows the average fraction of failed banks (solid line with squares) as a function of $\mu_{G}$. Due to the assumed homogeneity in banks' ability to withstand shocks, each square represents the probability the financial system will collapse for a given level of macroeconomic shock. As $\mu_{G}$ approaches 0.09 , the probability of system failure accelerates towards unity. There is an inflection point associated with $\mu_{G} \approx 0.085$. Here, the probability mass is equally distributed between the two modes of the aggregate loss distribution, representing the 'phase transition' or 'tipping point' of the complex financial system. For macroeconomic shocks above this level, the financial system will always collapse.

Figure 8 plots the aggregate loss distribution for the entire banking system for the stressed scenario where $\mu_{G}=0.078$. As can be seen, the losses under the adverse scenario are orders of magnitude greater than those in the baseline and the distribution is bi-modal. The probability mass is concentrated around (a) small losses of around $3 \%$ of system assets; and (b) a few extreme instances where around $11 \%$ of system assets are lost. In these extreme cases, the entire financial system collapses.

\subsection{Feedback effects}

We now investigate the effects of asset firesales and the withdrawal of bank lending to firms on the aggregate loss distribution. When banks are in distress and losses mount in excess of a trigger threshold, $\alpha$, of their capital buffer, they sell their holdings of equities and simultaneously tighten their lending to firms. The withdrawal of credit from remaining firms increases their probability of default. As further credit losses mount, the feedback effects of reduced bank lending amplifies the losses to banks and, together with the mark-to market effects of firesales, contributes to further financial instability.

We initially focus on the pure macroeconomic feedback effect of a credit crunch and abstract away from the possibility of any distress fire sales. In this case, $\lambda=0$. Thus, with $\psi=6.25 \times 10^{-5}$, we find no shift in the tipping point $\mu_{G}^{c}=0.078$. However, as figure 7 indicates the average fraction of failed banks is higher, as indicated by an upward shift of the curve in figure 9 . In the case of pure firesale effect, i.e., $\psi=0$, figure 9 shows the with $\lambda=0.7$, the minimum critical quantum of credit risk necessary to instigate system collapse is brought forward sharply to $\mu_{G}^{c}=0.037$. The average fraction of failed banks again shows the probability of system-wide failure. 
Allowing for the possibility that banks tighten credit conditions once they opt to engage in firesales further brings forward the first instance of system failure. Our calibration suggests that $\mu_{G}^{c}=0.031$ in this case and, as Figure 9 shows, the probability of system failure is greater for all values of $\mu_{G}$. The intuition is straightforward. In the first round, the tightening of credit by banks pushes further firms into bankruptcy, amplifying the extent of credit losses among banks. The ensuing distress of some banks leads to further firesales and a second round of credit tightening that further raises the probability of firm default. The cycle only terminates once the entire banking system fails.

As our results make clear, macroeconomic feedbacks are less substantial than firesales in our calibration. Indeed, both are difficult to calibrate meaningfully. While our firesale calibration is based on Mitchell et.al (2007), our ability to calibrate the macroeconomic feedbacks is wayward. While it may well be that this feedback is more substantial, the combined effects of both the firesale and macroeconomic feedbacks appear plausible. A through calibration of these mechanisms is beyond the scope of this paper and is an avenue for future analysis.

\subsection{A more realistic setting - heterogeneity of capital buffers}

Our depiction of financial fragility has been extremely stark - a change in the size of a credit shock around a critical value determines whether the entire network collapses or not. More realistically, one might expect situations in which intermediate outcomes obtain, in which only some banks fail but the rest of the system continues to function. In particular, shocks may be unable to spread once they reach very well capitalized banks.

We therefore relax the assumption that all banks have the same capital buffer, and allow it to vary from institution to institution. The capital-asset ratio, $\pi$, is now drawn from a uniform distribution with support [0.04, 0.24], more representative of the sort of buffers likely to be held by banks in some countries.

Figure 10 depicts a much richer set of results. We note, for example, that for $\mu_{G}=0.0375$, on average $2.8 \%$ of banks default. The banks that fail are both foreign and domestic. In particular instances of the simulations, 219 banks collapsed ( $85 \%$ of the the total system), while the few remaining, by virtue of higher capital buffers are saved. As $\mu_{G}$ increases to 0.0475 a similar conclusion is drawn. On average $91 \%$ or 234 banks in the system collapses. Once again, a few banks are found to be sufficiently well capitalized to survive the shock and feedback effects.

The highest default rates between 1920 and 2006 were, $1.7 \%$ for investment grade - ratings class $\mathrm{A}$ - firms and $11.1 \%$ for speculative grade - ratings class $\mathrm{Ba}-$ firms. (Moody's (2007)). These higher default rates were witnessed, in particular, during the Great Depression, which was a period of significant bank failures. In our 
model, these figures correspond to a probability of default for the average of 4.5 $\%$, which is generated by taking $\mu_{G}=0.045$. With liquidity and macro-feedback effects switched on and allowing banks to have heterogenous levels of capital in our model, we find that with $\mu_{G}=0.045$ a significant fraction ( $89 \%$ ) of the entire banking system collapses, on average.

\section{5. "Stress testing"}

In the wake of the global financial crisis, policy-makers have begun to subject banking systems to "stress tests". While we cannot do full justice to such exercises, out model is well versed to provide a compelling caricature of these tests that include both macroeconomic feedback and asset firesales. Moreover, our use of a random graph structure sidesteps the challenge to regulators of assessing the true scale of network connections due to complex financial products.

Specifically, we may ask how well domestic banks absorb corporate exposure loss rates of around $4.5 \%\left(\mu_{G}=0.044\right)$ and a $35 \%$ haircut of equity exposures stemming from a $20 \%$ equity price fall $(\lambda=0.37)$. These are the sorts of shocks being considered by policy-makers in contemporary bank stress test exercises.

Under this scenario we find that there are no bank failures in $67 \%$ of the simulated instances. However, in the remainder $33 \%$ of cases we have, on average, $200(78 \%)$ foreign and domestic banks failing. This implies that an overall average of $25 \%$ of banks fails. In the instances where no banks default, the losses solely due to corporate defaults amount to $1.8 \%$ of total system assets. However, in the remainder of instances, we have, on average $19 \%$ of all assets being wiped out.

The high average percentage of bank failures may be attributed to key modeling assumptions in our model, specifically the inclusion of macroeconomic and firesale feedback loops. These elements exacerbate shocks to the banking system, as discussed in Sections 4.2 and 4.3, thereby heightening the fragility of the financial system. Secondly, we take a 100\% LGD on interbank exposures. This assumption is stark and intended to be purely illustrative. Actual LGDs are likely to be less ${ }^{8}$. Taking, as we do, a loss rate of $100 \%$ amplifies losses due to bank defaults, which further contributes to the degradation of systemic stability. Finally, a third exacerbating factor is that we do not allow banks to offset their losses by future expected earnings, which would have helped mitigate the cascade of failures.

${ }^{8}$ For instance, published results on loss rates (e.g. James (1991)), report a loss rate of $40 \%$ for banks. Relatedly, Altman and Kishore (1996) estimate the recovery rates (100-LGD \%) on defaulting bonds of financial institutions between 1978-1995 to be about $36 \%$, on average. However, recovery rates vary by type of institution: mortgage banks $68 \%$, finance companies, $46 \%$ and commercial banks, $29 \%$. 


\section{Conclusion}

Modern financial systems are characterized by complex interlinkages and a diverse set of agents. Our paper develops a general framework to gauge systemic stability in the presence of such linkages and heterogeneity. Calibrating the model using data on advanced country banking sector that is largely public, we illustrate how macroeconomic fluctuations, asset market liquidity, and network structure interact to determine aggregate credit losses and contagion. Although our calibration is broad-brush in nature to emphasize the qualitative results of the model, the results show how systemic stability might begin to be quantified in a statistical fashion, particularly when data about the reach of modern financial instruments is limited and shocks are international in nature.

A thorough understanding of both the qualitative and quantitative features of aggregate loss distributions in the banking system is important for policymakers concerned with systemic risk. Our findings indicate that macroeconomic shocks and asset price feedback effects intertwine to generate fat tails in these distributions and that large-scale financial disruption may be possible. We also show how the heterogeneity of bank balance sheets gives rise to more realistic situations in which some banks fail, but the overall system remains resilient.

The model clearly illustrates how complex financial systems are vulnerable to system-wide breakdown of the type observed during the recent global financial crisis. It can also be used to inform stress testing exercises. Drawing on the types of scenarios and shocks recently used by policymakers to gauge financial sector resilience, we find the model generates outcomes that are broadly plausible. In particular, the default rates in the corporate sector necessary to trigger a systemic financial event in the model are comparable to those witnessed during the Great Depression and also the recent crisis.

Our model imposes a number of simplifying restrictions on connectivity. Relaxing these restrictions and altering the topology of the network may affect risksharing and change the degree to which shocks are dispersed safely across the financial system. A thorough evaluation of changing the network linkages between and among different types of agent is a task we leave for future research. An even greater challenge is to incorporate more meaningful behavioral responses into this type of network model, whilst retaining the complexities in its structure. 


\section{A. A Statistical Model of the Financial System}

\section{A.1. Financial relationships between different types of agent}

The financial system consists of $N$ agents who belong to one of three types: (1) $N^{D}$ domestic banks; (2) $N^{I}$ international banks and (3) $N^{F}$ firms ${ }^{9}$, where $N=$ $N^{D}+N^{I}+N^{F}$.

Each agent is represented by a node on a directed graph and linked to each other through their assets, liabilities, and equity holdings. Specifically, for an agent $i$, an incoming link from agent $j$ represents an asset - either loans or equities - on $i$ 's balance sheet. Let the value of loans and equities from agent $i$ to $j$ be $A_{i j}, Q_{i j} \in \mathbb{R}^{+}$ respectively. Outgoing links represent an agent's liabilities with value $L_{i j} \in \mathbb{R}^{+}$.

Connections between agents of different types are formed randomly. The variables $c_{i j}, d_{i j} \in\{0,1\}$ denote whether agent $i$ holds a loan or equity assets against agent $j$. Thus, we write

$$
A_{i j}=c_{i j} S_{i j},
$$

and

$$
Q_{i j}=d_{i j} T_{i j},
$$

where $S_{i j}, T_{i j} \in \mathbb{R}^{+}$are random variables that describe the extent of the exposure.

The statistics of our random variables are governed by the type of the lending and borrowing agents, i.e., whether one or the other is a domestic or international bank or a firm. We define $\rho_{D I}\left(S_{i j}\right)$ as the probability density function (PDF) of loans from domestic bank, labeled $i$, to the international bank, labeled $j$. Similarly, we can define the PDF $\rho_{I F}\left(T_{i j}\right)$ of equity holdings between the international bank $i$ and firm $j$. Considering all possible combinations of agent types, and hence lending arrangements, the statistics for sizes of loan and equity holdings is governed by 18 different probability distributions.

For the connectivity coefficients $c_{i j}$ and $d_{i j}$ as well we can apply a similar procedure to define $\tilde{\rho}_{D I}\left(c_{i j}\right)$ as the probability mass function (PMF) for the presence (or absence) of a loan from domestic bank $i$ to foreign bank $j$. Similarly, $\tilde{\rho}_{I F}\left(d_{i j}\right)$ defines the PMF determining the probability with which international bank $i$ holds equity of firm $j$ in our financial system. The financial relationships between different types of agent can now be given a convenient matrix form. Their interactions are summarized by the matrix

$$
\mathbf{F}=\left(\begin{array}{ccc|ccc}
\mathbf{A}^{D D} & \mathbf{A}^{D I} & \mathbf{A}^{D F} & \mathbf{Q}^{D D} & \mathbf{Q}^{D I} & \mathbf{Q}^{D F} \\
\mathbf{A}^{I D} & \mathbf{A}^{I I} & \mathbf{A}^{I F} & \mathbf{Q}^{I D} & \mathbf{Q}^{I I} & \mathbf{Q}^{I F} \\
\mathbf{A}^{F D} & \mathbf{A}^{F I} & \mathbf{A}^{F F} & \mathbf{Q}^{F D} & \mathbf{Q}^{F I} & \mathbf{Q}^{F F}
\end{array}\right)
$$

\footnotetext{
${ }^{9}$ We furthermore denote by $\mathcal{N}^{D}, \mathcal{N}^{I}$ and $\mathcal{N}^{F}$ the set of domestic banks, international banks and firms, respectively.
} 
where $\mathbf{A}^{X Y}$ and $\mathbf{Q}^{X Y}$ are matrices of exposures from type $\mathrm{X}$ agents to other type $\mathrm{Y}$ agents, whose elements are $c_{i j} S_{i j}$ and $d_{i j} T_{i j}$, respectively, with $i \in \mathcal{N}^{X}$ and $j \in \mathcal{N}^{Y}$.

The forms used for our exposure PDFs and connectivity PMFs is spelt out in the calibration section.

\section{A.2. Financial relationships between agents of the same type}

We here assume that all core domestic banks holds assets against every other domestic bank. Hence in matrix $\mathbf{A}^{D D}$ we have that $c_{i j}=1$. This forms a complete network of the core banks through their lending relationships. Firms do not hold assets or equity against each other or against domestic and international banks. Hence the matrices $\mathbf{A}^{F D}, \mathbf{A}^{F I}, \mathbf{A}^{F F}, \mathbf{Q}^{F D}, \mathbf{Q}^{F I}$ and $\mathbf{Q}^{F F}$ are all equal to zero.

Interactions between international banks take place on a small-world network. Such networks are characterized by (i) their clustering coefficient, which reflects the clique-like relationship between a node and its nearest neighbors; (ii) longrange links between 'distant' nodes which result in a short average path length (i.e. a short average number of links between any two nodes).

The connectivity coefficients between international banks, i.e., $c_{i j}$, with $i, j \in$ $\mathcal{N}^{I}$, are constructed using the algorithm proposed by Watts and Strogatz (1998). Pictorially, we arrange the nodes of international banks in a ring and connect each node to its' $2 \kappa$ nearest neighbors. Next, starting with the first bank, we add with probability $p$ a 'long-range' link to another bank outside its' nearest-neighborhood. We perform this random draw and 'long-range' link addition with probability $p$ a total of $2 \kappa$ times for the first bank. This procedure is iterated over all international banks. The total number of 'long-range' links is $N^{I} 2 \kappa p$.

Taken together, our assumptions on connectivity lead to a restricted matrix and imply that our financial system can be represented as

$$
\mathbf{F}^{\prime}=\left(\begin{array}{ccc|c}
\mathbf{A}^{D D} & \mathbf{A}^{D I} & \mathbf{A}^{D F} & \mathbf{Q}^{D F} \\
\mathbf{A}^{I D} & \mathbf{A}^{I I} & \mathbf{A}^{I F} & \mathbf{Q}^{I F}
\end{array}\right) .
$$

\section{A.3. Bank balance sheets}

We now describe the bank balance sheets depicted in Figure formally. The total assets of bank $i$, which may be either domestic or foreign, is

$$
A_{i}=\sum_{j \in \mathcal{N}_{i}^{D}} S_{i j}+\sum_{j \in \mathcal{N}_{i}^{I}} S_{i j}+\sum_{j \in \mathcal{N}_{i}^{F}} S_{i j}+\sum_{j \in \mathcal{M}_{i}^{F}} T_{i j}+B_{i},
$$

where

$$
\mathcal{N}_{i}^{X}=\left\{j \in \mathcal{N}^{X} \backslash i \mid c_{i j}=1\right\} \text { and } \mathcal{M}_{i}^{F}=\left\{j \in \mathcal{N}^{F} \backslash i \mid d_{i j}=1\right\},
$$


and $B_{i}$ denotes the level of safe assets such as government bonds. The set $\mathcal{N}_{i}^{X}$ denotes the set of institutions $j$ (type $X$ ) against whom bank $i$ holds an asset. Similarly, $\mathcal{M}_{i}^{X}$ denotes the set of firms $j$ whose shares bank $i$ owns. The total liabilities are

$$
L_{i}=\sum_{j \in \tilde{\mathcal{N}}_{i}^{D}} S_{j i}+\sum_{j \in \tilde{\mathcal{N}}_{i}^{I}} S_{j i}+K_{i}+D_{i},
$$

where $D_{i}$ denotes external liabilities such as customer deposits and the initial capital buffer $K_{i}=\pi A_{i}$ is a fixed fraction $\pi \in(0,1)$ of assets on the balance sheet. As before, $\tilde{\mathcal{N}}_{i}^{X}=\left\{j \in \mathcal{N}^{X} \backslash i \mid c_{j i}=1\right\}$ denotes the set of banks $j$ (type $X$ ) to whom bank $i$ has a liability.

If the initial assets of each bank drawn from the asset distribution exceeds initial liabilities, the liability-side of the balance sheet is 'topped' up by customer deposits to ensure that total assets are equal to total liabilities. Conversely, if liabilities exceed assets, the difference is accounted for on the asset side by holdings of government bonds.

\section{A.4. Crisis dynamics and contagion}

In our simulations, a bank will default if its total losses are greater than its capital buffer. We consider a two-state model, i.e., during each instance of the internal simulation time $t \in \mathbb{N}$, bank $i$ is either solvent $\left(v_{i}(t)=0\right)$ or it has defaulted $\left(v_{i}(t)=1\right)$. Defining the total losses incurred by bank $i$ as $\mathcal{L}_{i, \text { tot }}(t) \geq 0$, we obtain the following update rule:

$$
v_{i}(t+1)=\Theta\left(\mathcal{L}_{i, \text { tot }}(t)-K_{i}\right),
$$

where $\Theta(. .$.$) is the Heaviside function. In what follows, we specify the various$ components that contribute to bank losses.

A crisis is instigated by shocks to firms. We model firm default using a Bernoulli model, of the sort widely used in the credit risk literature (Gordy (2000)) and in the risk management industry. Similar to that of banks, we define the state of firm $\ell$ as being either solvent $\left(\mu_{\ell}(t)=0\right)$ or defaulted on its' loans to banks $\left(\mu_{\ell}(t)=1\right)$. Furthermore, firms are classified according to their creditworthiness, which is quantified by a probability of default $\operatorname{PD}_{\ell}(t) \in(0,1)$, for firm $\ell$ at time $t$. All firms fall into one of two categories: (i) investment-grade (IG) or (ii) non-investment / speculative grade (NIG). The probability of default $\operatorname{PD}_{\ell}^{\eta}(t)$ for firm $\ell$ (of grade $\eta$ ) at time $t$ is given by

$$
\operatorname{PD}_{\ell}^{\eta}(t)=R_{\ell}(\eta)+\mu_{G}+\psi\left(\sum_{i \in \mathcal{W}_{\ell}^{D}} \phi_{i}(t)+\sum_{i \in \mathcal{W}_{\ell}^{I}} \phi_{i}(t)\right),
$$


where $R_{\ell}(\eta) \in(0,1)$ is drawn from the distribution of $\rho_{\eta}(P D)$ for firms in grade $\eta$. The second term $\mu_{G}$ reflects an aggregate economy wide shock to all firms. The final term in the equation above reflect the macro-feedback loop. The indicator variable $\phi_{i}(t)$ denotes whether bank $i$ 's intent to perform a firesale $\left(\phi_{i}(t)=1\right)$ or abstain $\left(\phi_{i}(t)=0\right)$ from such drastic action. If bank $i$ is forced to perform a firesale, the action is accompanied by the bank cutting back on its lending to firms. This act leaves firms more vulnerable to default, thereby resulting in an increase of their PD by an amount $\psi$. Thus for each bank (domestic and international) performing a firesale, against whom firm $\ell$ has borrowed (denoted by the set $\mathcal{W}_{\ell}^{X}=\{i \in$ $\left.\left.\mathcal{N}^{X} \mid c_{i \ell}=1\right\}\right)$, there will be a contribution $\psi$ increase to the firms' PD.

Firms default according to a series of Bernoulli trials, i.e., starting with all firms being solvent, at specific times $t^{\star}$, each firm $\ell$ will default independently of others with probability $\operatorname{PD}_{\ell}^{\eta}\left(t^{\star}\right)$. These times $t^{\star}$ occur each time the PDs of firms are incremented by factors of $\psi$ due to the firesales and subsequent cutting back of lending by the banks.

Default severs the connections (loans and shares) between banks and firms. We assume a zero recovery rate for loans and also suppose that share prices of the defaulted firms drop to zero. ${ }^{10}$ Thus, losses from firms for bank $i$ are:

$$
\mathcal{L}_{i, \mathrm{f}}(t)=\sum_{j \in \mathcal{N}_{i}^{F}} S_{i j} \mu_{j}(t)+\sum_{j \in \mathcal{M}_{i}^{F}} T_{i j} \mu_{j}(t) .
$$

Bank $i$ will default at time $t$ from the firm credit shocks if $\mathcal{L}_{i, \mathrm{f}}(t)>K_{i}$.

Contagion in the financial system may spread through direct financial linkages. If bank $i$ defaults, then another bank $j$ holding assets against bank $i$, will suffer losses. At this point, we assume that the financial counterparties of defaulting banks lose all of their interbank assets held against that bank. ${ }^{11}$ At time $t$ the counter-party losses for bank $j$ amount to

$$
\mathcal{L}_{j, \mathrm{c}}(t)=\sum_{k \in \mathcal{N}_{j}^{D}} S_{j k} \eta_{k}(t)+\sum_{k \in \mathcal{N}_{j}^{I}} S_{j k} \eta_{k}(t)
$$

Contagion may also spread indirectly as a result of mark-to-market losses on balance sheets brought on by fire sales of assets by banks in distress. As any

\footnotetext{
${ }^{10}$ The stylized zero recovery rate assumption simplifies the mathematical structure of the model. And, though we adopt it in our simulations, the framework allows for this assumption to be relaxed in a straightforward manner.

${ }^{11}$ This assumption is likely to be realistic in the midst of a crisis: in the immediate aftermath of a default, the recovery rate on loans and the timing of economic recovery will be highly uncertain and those providing banks' funding are likely to assume the worst-case scenario. Gai and Kapadia (2010) show that the qualitative features of these types of model are robust to relaxing this assumption.
} 
individual bank incurs losses, it is likely to take defensive actions to protect itself from failure. One option, exercised by some institutions since the advent of the current financial crisis, is for the bank to sell assets. Therefore, we allow banks to sell equities when they are in distress (we suppose that debt is completely illiquid and therefore cannot be sold). Specifically, banks engage in fire sales of equities once losses mount above a certain fraction $\alpha \in(0,1)$ of their capital, i.e.,

$$
\phi_{j}(t)=\Theta\left(\mathcal{L}_{j, \mathrm{c}}(t)+\mathcal{L}_{j, \mathrm{f}}(t)-\alpha K_{j}\right) .
$$

Let $Q(t) \geq 0$ be the equity held by banks participating in a fire sale at time $t$, i.e.,

$$
Q(t)=\sum_{i \in \mathcal{N}^{D}} \phi_{i}(t)\left(\sum_{\ell \in \mathcal{M}^{F}} T_{i \ell}\right)+\sum_{i \in \mathcal{N}^{I}} \phi_{i}(t)\left(\sum_{\ell \in \mathcal{M}^{F}} T_{i \ell}\right),
$$

and $Q>0$ be the total equity held by all banks. The dynamics of the equity price, $q(t) \geq 0$, are determined by a form of "cash in the market" pricing (Allen and Gale (2005); Cifuentes et.al (2005)), where the price is reducing in the ratio of the equities for sale to the quantity of equities not being sold, a proxy for nondistressed potential buyers. We therefore write

$$
q(t+1)=q(t)\left(1-\lambda \frac{Q(t)}{Q-Q(t)}\right)
$$

where $\lambda \in \mathbb{R}^{+}$is a parameter that measures the price impact of a fire sale. ${ }^{12}$ If the market is extremely liquid, $\lambda=0$ and there is no price impact from asset sales, whereas $\lambda>0$ implies that equity prices fall sharply for a given amount of distressed assets on the market.

When the equity price falls, banks incur mark-to-market losses on their equity holdings. Bank $j^{\prime}$ s total losses at time $t$ are thus given by

$$
\mathcal{L}_{j, \mathrm{tot}}(t)=\mathcal{L}_{j, \mathrm{c}}(t)+\mathcal{L}_{j, \mathrm{f}}+\sum_{k \in \mathcal{M}^{F}} T_{j k}(q(0)-q(t))\left[1-\mu_{k}(t)\right] .
$$

where the last term refers to losses incurred due to a fall in equity prices of firms that did not default from the initial shock.

When one bank has defaulted, related counterparty and mark-to-market losses may cause other banks to default. This process continues iteratively, with contin-

\footnotetext{
${ }^{12}$ While the prescribed form of equity price captures an acceleration in price fall as more equity is dumped onto the market, we must explicitly demand that negative prices are not allowed. This may be achieved by multiplying the right-hand side of (14) by $\Theta(q(t))$.
} 
ually updating counterparty and mark-to-market losses, until no further banks are pushed into default. ${ }^{13}$

\section{B. Principle of maximum entropy}

Let us define $P(X)$ to be the probability distribution for the random variable $X \in \mathbb{N}$. We shall, for the moment concentrate on the case of discrete random variables, but the theory may be readily generalized to the case of continuous random variables.

Suppose we can observe and empirically measure the first $M$ raw moments of the distribution, which we write as

$$
\mu_{n}=\sum_{x \geq 0} x^{n} P(X=x), \quad n=0,1, \ldots, M .
$$

The $n=0$ case simply reflect that the probability distribution must be normalized, i.e., $\mu_{0}=1$.

Our goal is to find the least biased form for $P(x)$ that satisfies the constraints give by Eq. (16). The principle of maximum entropy states that the distribution we seek is the one that maximizes the information entropy. We can solve for this distribution from the Lagrange function

$$
S[P]=-\sum_{x \geq 0} P(x) \log P(x)+\sum_{n=0}^{M} \lambda_{n}\left[\sum_{x \geq 0} x^{n} P(X=x)\right],
$$

where the $\lambda_{n} \in \mathbb{R}$ indicate the Lagrange multipliers that we must solve for. The first term in Eq. (17) gives us the information entropy. Our maximal entropy distribution is given by solving $\partial S[P] / \partial P(x)=0$, which yields

$$
P(x)=\exp \left(-\left[\lambda_{0}+\lambda_{1} x+\lambda_{2} x^{2}+\ldots+\lambda_{M} x^{M}\right]\right),
$$

where

$$
\begin{aligned}
\lambda_{0} & =\log Z \\
& =\log \sum_{x \geq 0} \exp \left(-\left[\lambda_{0}+\lambda_{1}\langle x\rangle+\lambda_{2}\left\langle x^{2}\right\rangle+\ldots+\lambda_{M}\left\langle x^{M}\right\rangle\right]\right)
\end{aligned}
$$

\footnotetext{
${ }^{13}$ Eisenberg and Noe (2001) demonstrate that, following an initial default in such a system, a unique vector which clears the obligations of all parties exists.
} 
enforces the normalization of the probability distribution and the Lagrange multipliers are given as the solutions to the set of $M+1$ equations

$$
\mu_{n}=\int \mathrm{d} x x^{n} \exp \left(-\sum_{m=0}^{M} \lambda_{m} x_{m}\right), \quad n=0,1, \ldots M .
$$

Closed form analytical expressions for the distributions are available only when $M \leq 2$. For $M=0$, we only specify that the probability distribution must be normalized. This corresponds to Laplace's principle of indifference, which dictates that if we have no prior information to distinguish between different states of a system we must associate equal probability to each state. For $M=1$, we impose that the distribution must be normalized and specify its' mean. If the mean is positive then we get an exponential distribution. Finally, when $M=2$ and the support for the random variable is the entire real axis, we obtain the Normal distribution function. For higher values of $M$ there is no closed for analytical expression and we must rely on numerical methods to solve for the distribution. In particular, we follow the method proposed by Mohammad-Djafari (1991) for the estimation. 


\section{References}

Altman, EL and VM Kishore (1996) Almost everything you wanted to know about recoveries on defaulted bonds, Financial Analysts Journal, vol. 52, pp. 57-64.

Aikman, D, Alessandri P, Eklund B, Gai P, Kapadia S, Martin E, Mora N, Sterne $\mathrm{G}$ and M Willison (2009), Funding liquidity risk in a quantitative model of systemic stability, Bank of England Working Paper, No. 372.

Alessandri, P, Gai P, Kapadia S, Mora N and C Puhr (2009), Towards a framework for quantifying systemic stability, International Journal of Central Banking, vol. 5, pp. 47-82.

Allen, F and A Babus (2008), Networks in finance, in Kleindorfer, P and J Wind (eds), Network-based Strategies and Competencies, Wharton School Publishing, University of Pennsylvania.

Allen, F and D Gale (2000), Financial contagion, Journal of Political Economy, vol. 108, pp. 1-33.

Allen, F and D Gale (2005), From cash-in-the-market pricing to financial fragility, Journal of the European Economic Association, vol. 3, pp. 535-546.

Bianconi, G (2009), The entropy of network ensembles, Physical Review E, vol. 79, pp. 036114.

Bank for International Settlements (2008), Consolidated banking statistics, http://www.bis.org/statistics/about_banking_stats.htm.

Bank of England (2007a), Financial stability report, April, Issue 21.

Bank of England (2007b), Credit conditions survey, September.

Castiglionesi, F and N Navarro (2007), Optimal fragile financial networks, Tilburg University Discussion Paper, \#2007-100.

Cifuentes, R, Ferrucci, G and H Shin (2005), Liquidity risk and contagion, Journal of the European Economic Association, vol. 3, pp. 556-566.

Eisenberg, L and T Noe (2001), Systemic risk in financial systems, Management Science, vol. 47, pp. 236-249.

Elsinger, H, Lehar, A and M Summer (2006), Using market information for banking systems, International Journal of Central Banking, vol. 27, pp. 137-65. 
Errais, E, Giesecke, K and LR Goldberg (2010) A?ne point processes and portfolio credit risk, SIAM Journal on Financial Mathematics, vol. 1, pp. 642665.

Foglia, A (2009), Stress testing credit risk: a survey of authorities' approaches, International Journal of Central Banking, vol. 5, pp 9-45.

Gai, P and S Kapadia (2010), Contagion in financial networks, Proceedings of the Royal Society A, vol. 466, pp. 2401-2423.

Gai, P, Haldane, S and S Kapadia (2011), Complexity, crises and contagion, Journal of Monetary Economics, vol. 58, forthcoming.

Gauthier, C, Lehar, A and M Souissi (2010), Macroprudential capital requirements and systemic risk, Bank of Canada Working Paper, No. 2010-4.

Giesecke, K and S Weber (2004), Cyclical correlations, credit contagion, and portfolio losses, Journal of Banking and Finance, vol. 28, pp. 3009-3036.

Giesecke, K and S Weber (2006), Credit contagion and aggregate losses, Journal of Economic Dynamics and Control, vol. 30, pp. 741-767.

Gordy, M (2000), A comparative anatomy of credit risk models, Journal of Banking of Finance, vol. 24, pp. 119-149.

Haldane, A (2009), Rethinking the financial network, Bank of England, www.bankofengland.co.uk/publications/ speeches/2009/speech386.pdf.

Hatchett, J and R Kühn (2009), Credit contagion and credit risk, Quantitative Finance, vol. 9, pp. 373-382.

Horst, U (2007), Stochastic cascades, credit contagion and large portfolio losses, Journal of Economic Behavior and Organization, vol. 63, pp. 25-54.

Jackson, M (2008), Social and economic networks, Princeton University Press.

James, C (1991) The losses realized in bank failures, The Journal of Finance, vol. 46, pp. 1223-1242.

Leitner, Y (2005), Fragile financial networks, The Journal of Finance, vol. 60, pp. 2925-2953.

Longstaff, FA and A Rajan (2008), An empirical analysis of the pricing of collateralized debt obligations, The Journal of Finance, vol. 63, pp. 529563.

May, RM, Levin, S and G Sugihara (2008), Ecology for bankers, Nature, vol. 451, pp. 893-895. 
May, RM, and N Arinaminpathy (2010) Systemic risk: the dynamics of model banking systems, J. R. Soc. Interface, vol. 7, pp. 823-838.

May, RM, and AG Haldane (2011) Systemic risk in banking ecosystems, Nature, vol. 469 , pp. 351355 .

Mitchell, M, Pedersen LH and T Pulvino (2007), Slow moving capital, American Economic Review, vol. 97, pp. 215-220.

Mohammad-Djafari, A (1991) A Matlab Program to Calculate the Maximum Entropy Distributions, in Maximum Entropy and Bayesian Methods: MaxEnt Proceedings, eds. T.W Grandy, Kluwer Academic Publ., pp. 221-233.

Moody's (2007), Corporate default and recovery rates, 1920-2006, Moody's Investors Service Global Credit Research, February.

Morris, S and HS Shin (2009) Illiquidity component of credit risk, mimeo, Princeton University.

von Peter, G (2007), International banking centers: a network perspective, $B I S$ Quarterly Review, vol. December, pp. 33-45.

Schuermann, T and S Hanson (2004), Estimating probabilities of default, Federal Reserve Bank of New York Staff Reports, no. 190, July.

Trichet, J-C (2008), The recent turbulence in global financial markets, Keynote Address to the New York University Global Economic Policy Forum, New York, 14 April.

Upper, C (2011), Simulation methods to assess the danger of contagion in interbank markets, Journal of Financial Stability, vol. 7, pp. 111-125

Watts, D and S Strogatz (1998), Collective dynamics of 'small world' networks, Nature, vol. 393, pp. 440-442. 


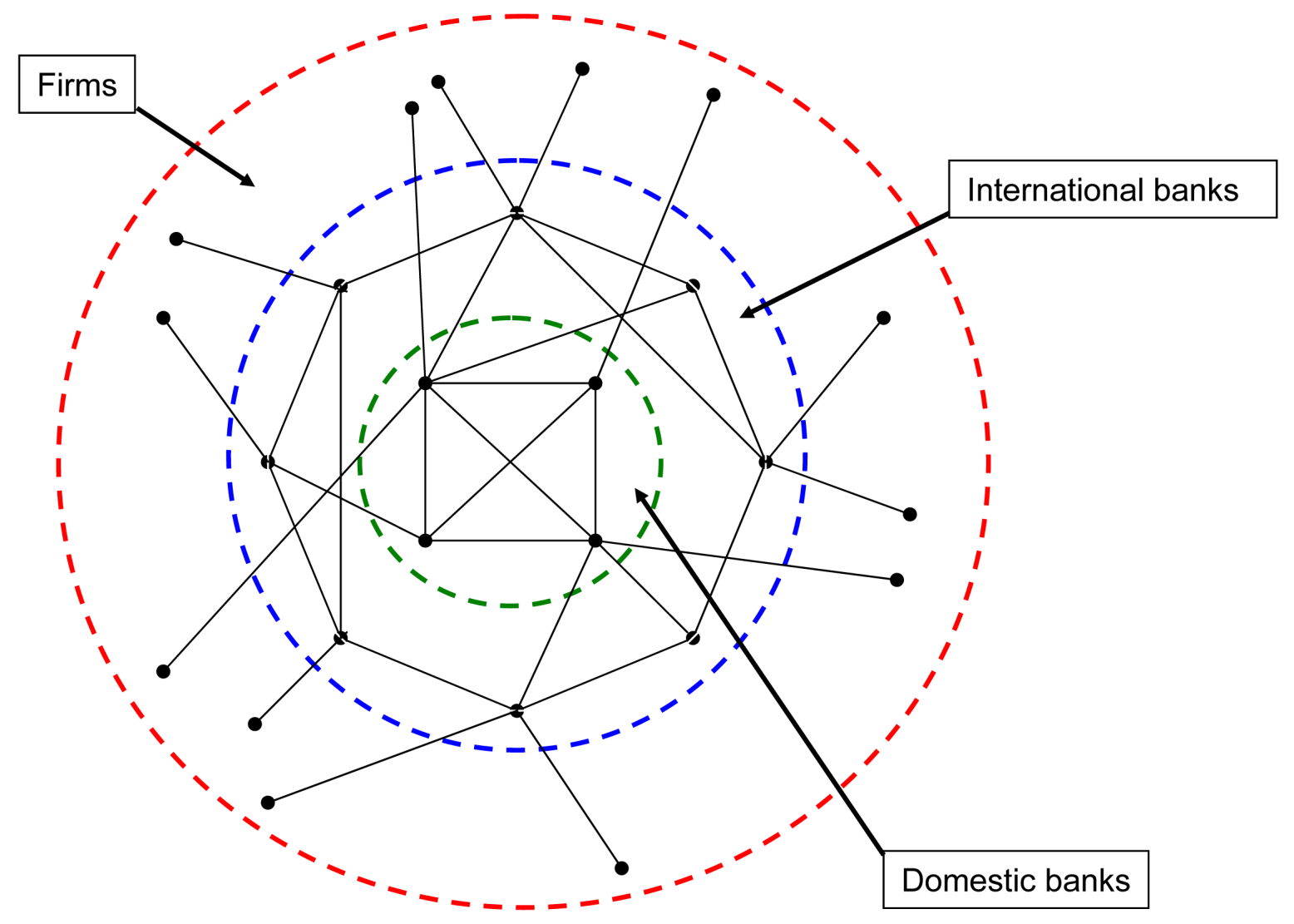

Figure 1: The stylized financial system where the filled circles - nodes - represent banks/firms, and the links between nodes depict credit or equity relationships. There are three distinct layers: (i) a core of domestic banks, (ii) a peripheral layer of international banks and (iii) an outer layer of firms. 


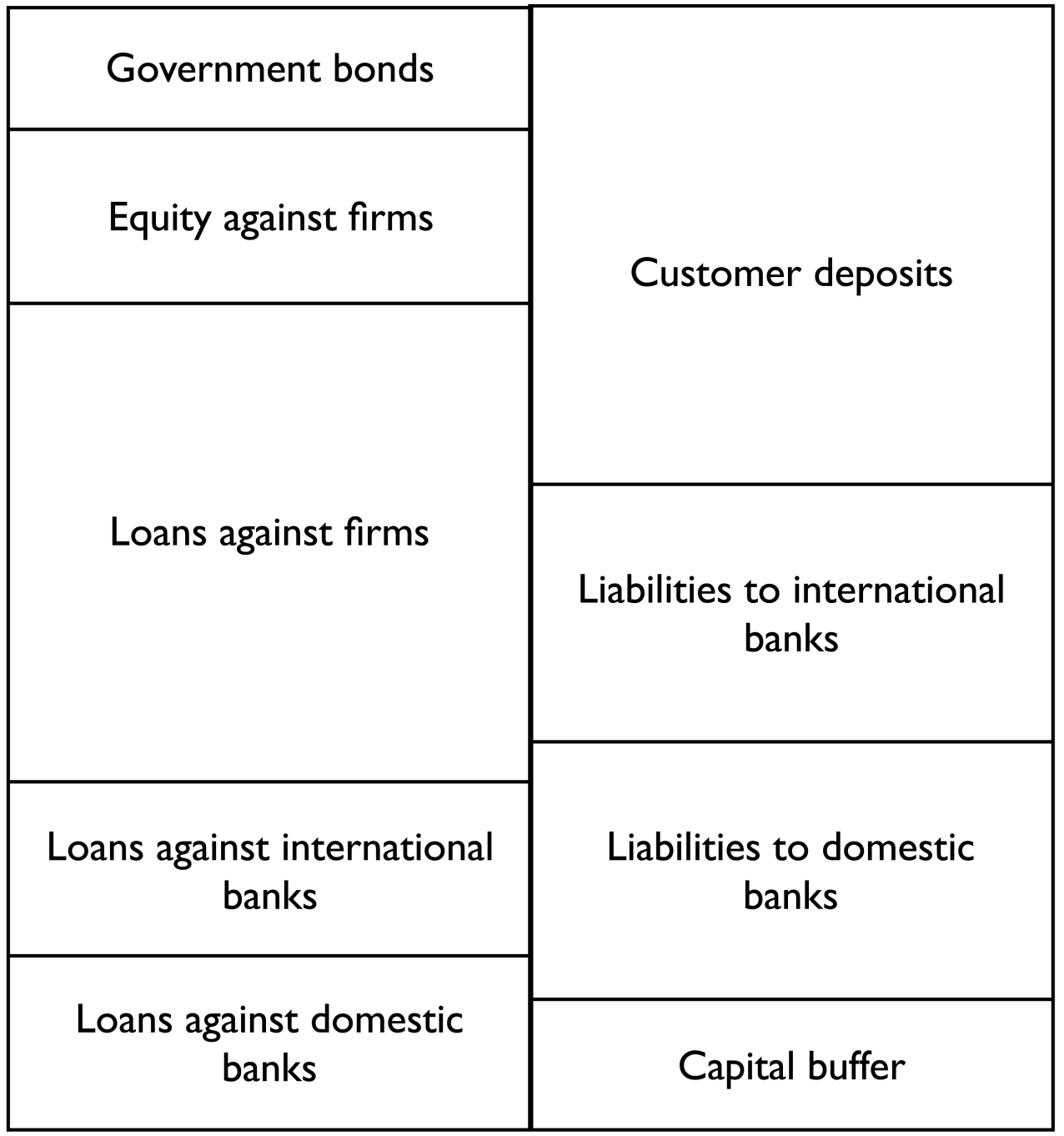

Figure 2: Typical balance sheet of a bank in the financial system. 


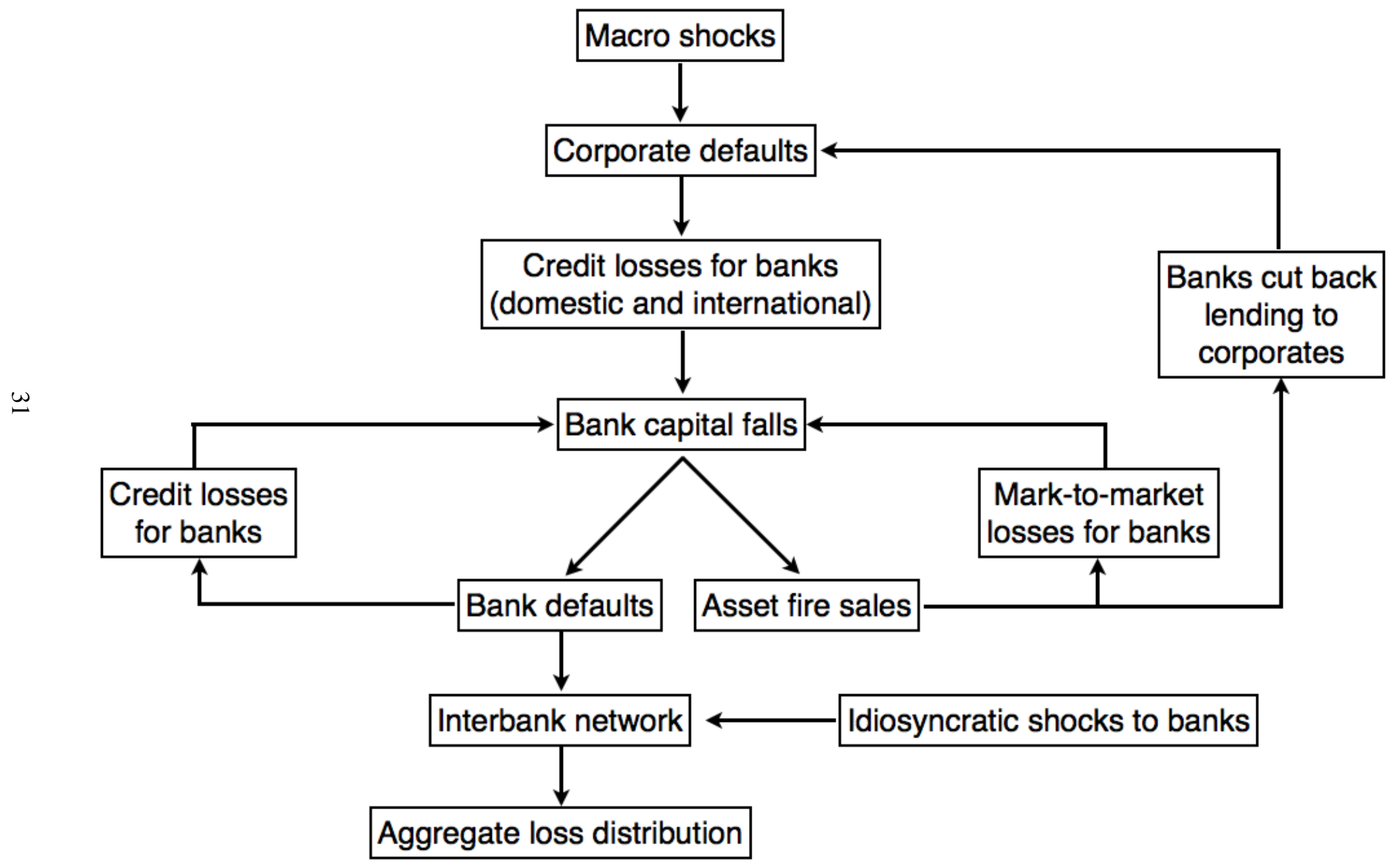



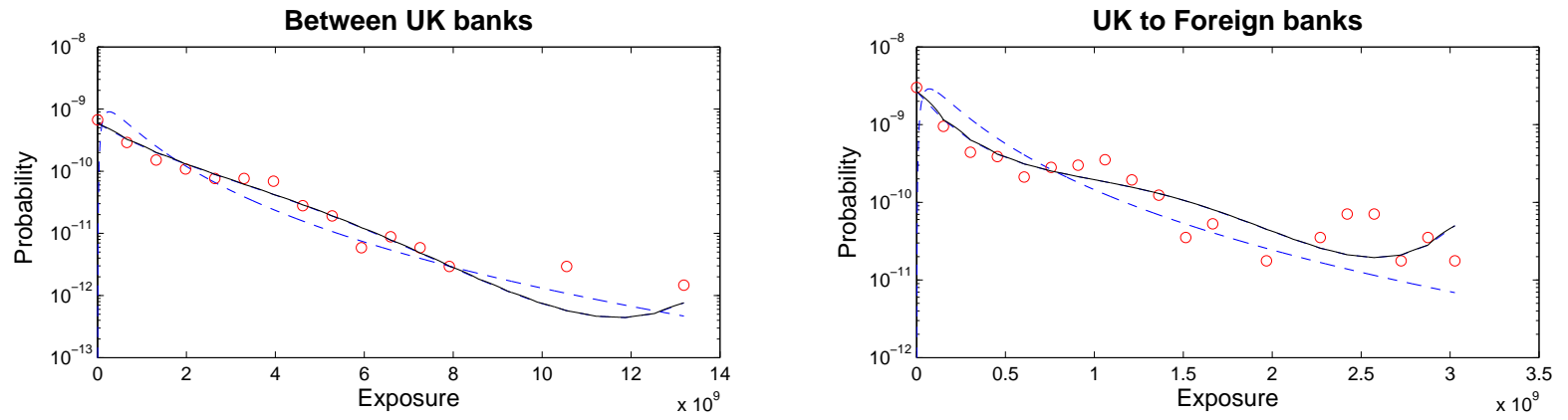

$\stackrel{w}{\sim}$
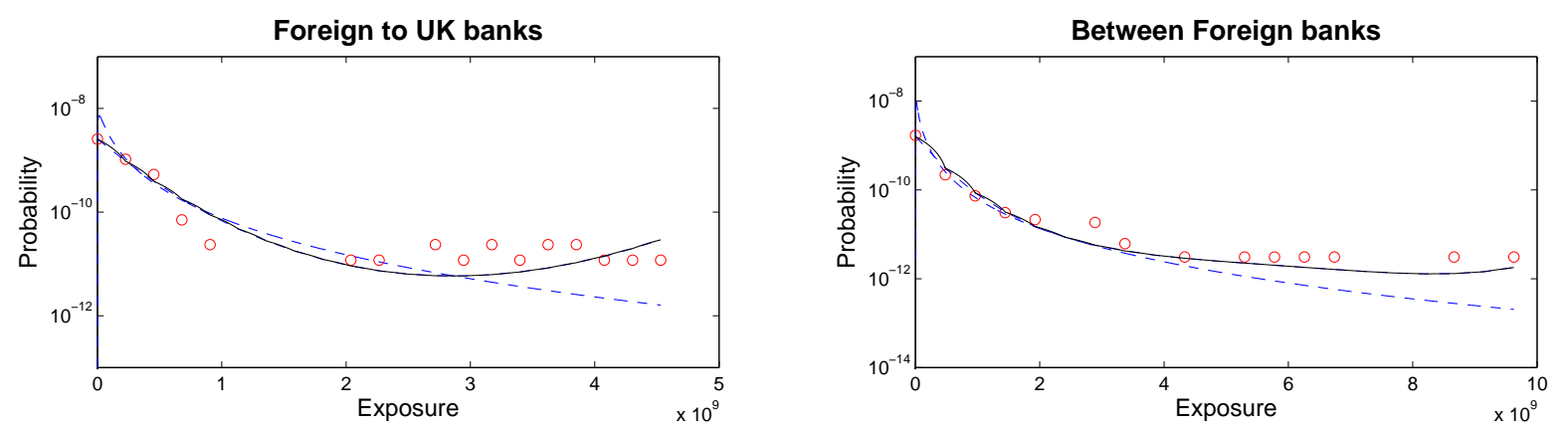

Figure 4: Empirical distributions (circles) for the inter-bank asset sizes on a Y-logarithmic axis, i.e., the probability has a logarithmic scale. We plot against the empirical distribution both the maximum-entropy distribution (solid line) and the fitted log-normal distribution (dashed line). 


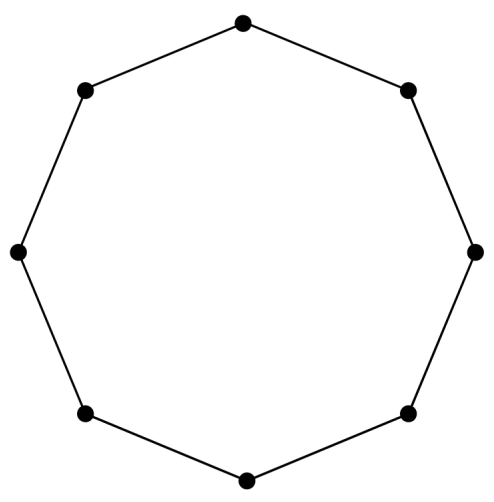

Regular network

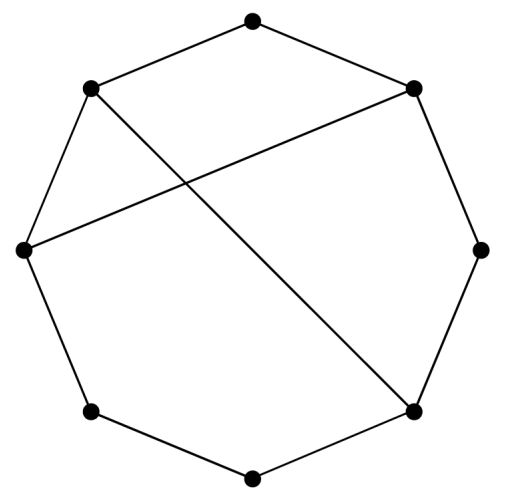

Small world network

Figure 5: The small world nature of international financial interlinkages. Starting with a regular lattice where each bank is connected to its' two nearest-neighbor banks (one on either side), we add 'long range' links at random (with probability $p$ ) between banks to get the small-world network. 


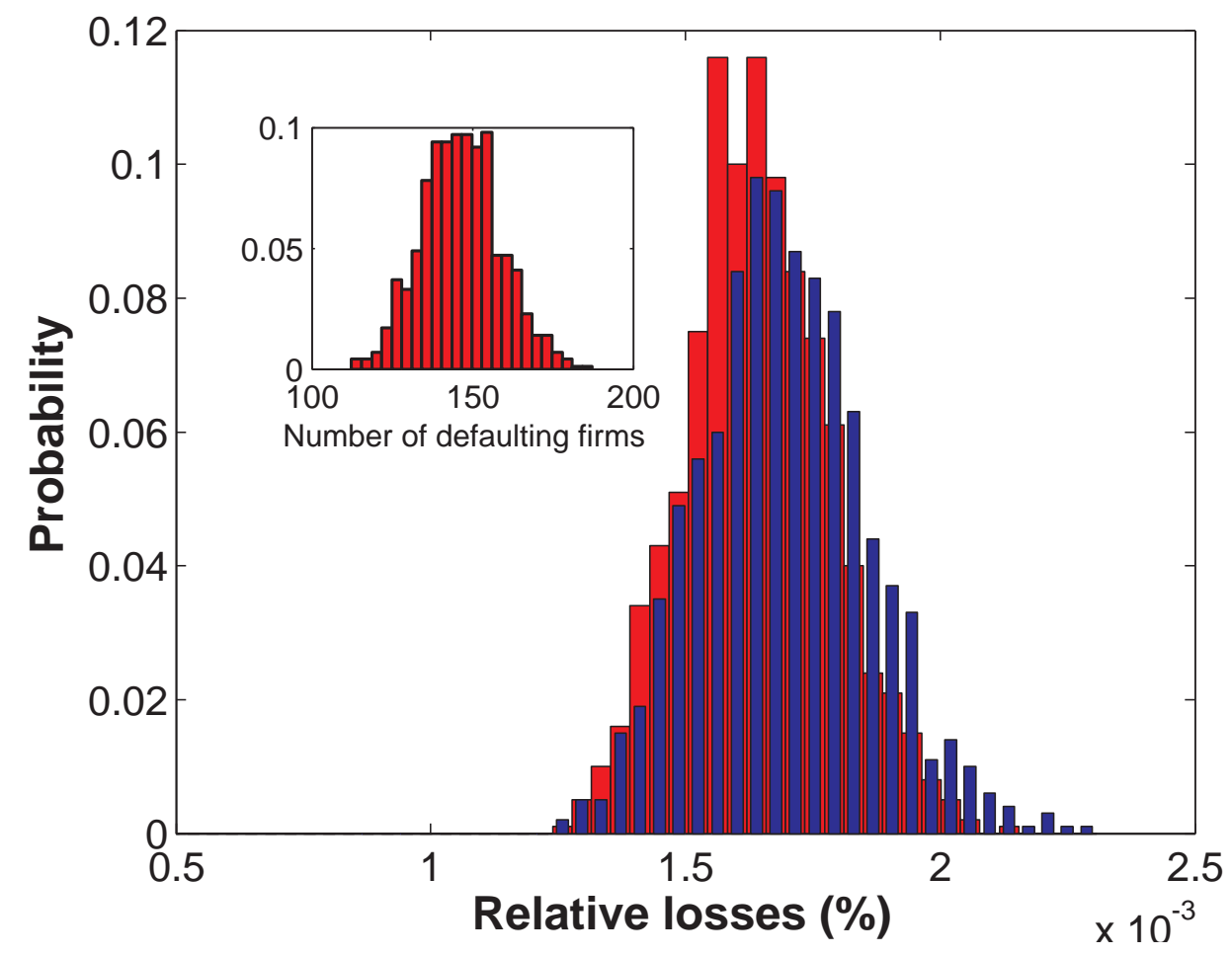

Figure 6: Distribution of losses relative to system assets for the entire banking network (red) and the UK banking network (blue) for the baseline scenario. In the inset we show the corresponding normalized histogram for the number of defaulted firms. 


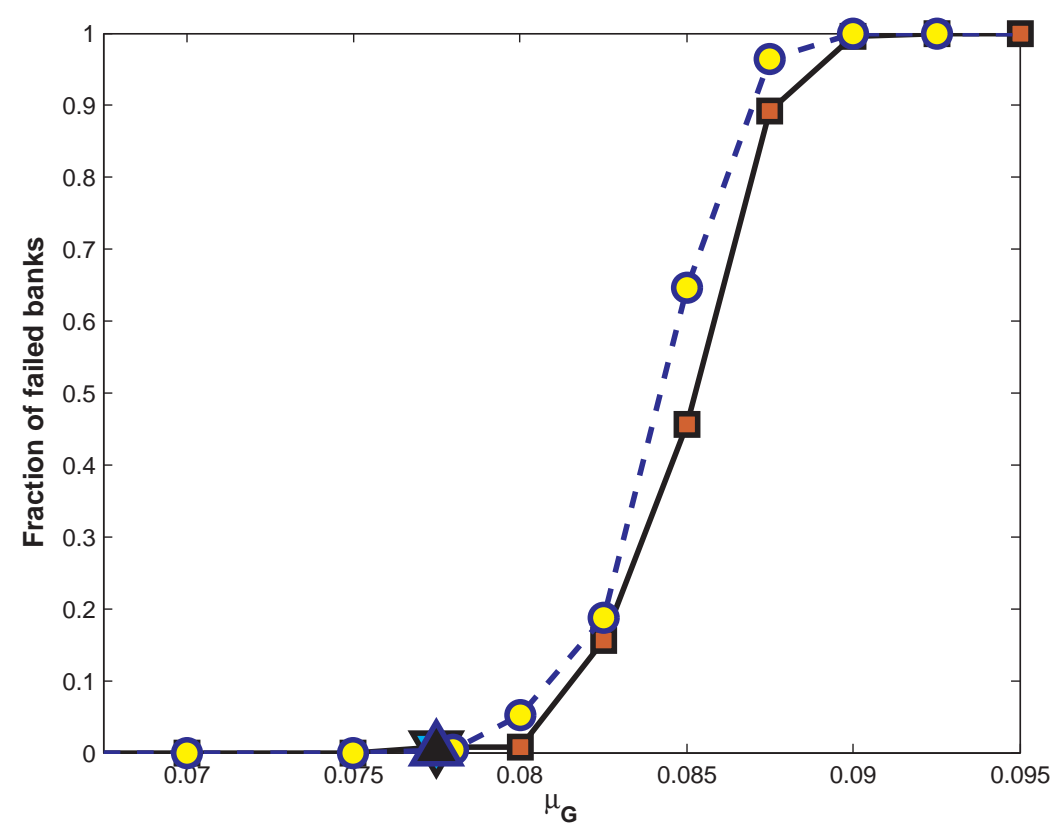

Figure 7: The average fraction of failed banks as a function of the aggregate macroeconomic shock, $\mu_{G}$. The initial instance of total system breakdown is indicated by the downward facing triangle. The dashed line represents the case with $\psi=6.25 \times 10^{-5}$ and $\lambda=0.0$. The upward facing triangle indicates the corresponding first instance of total breakdown. 


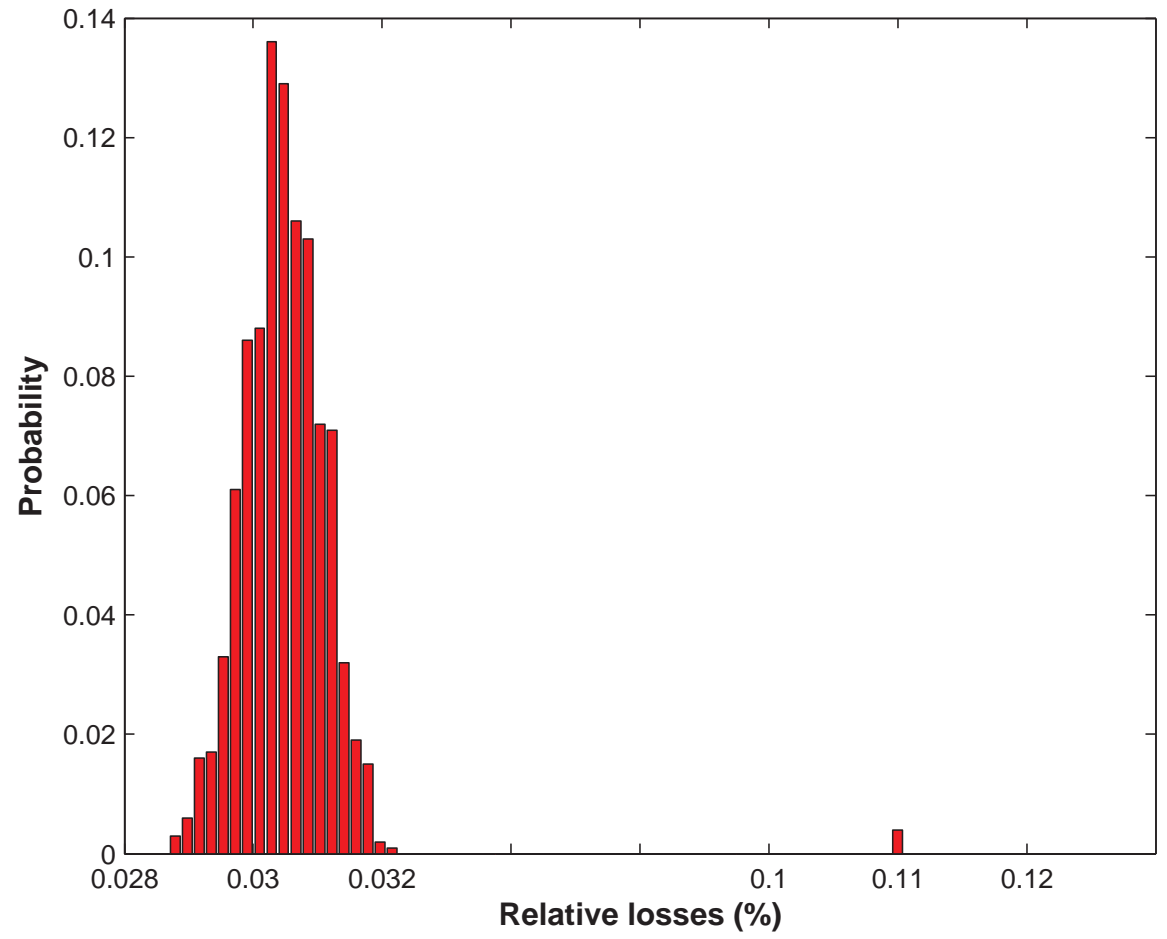

Figure 8: Loss distributions for the stressed aggregate macroeconomic shock scenario where $\mu_{G}=$ 0.078 . 


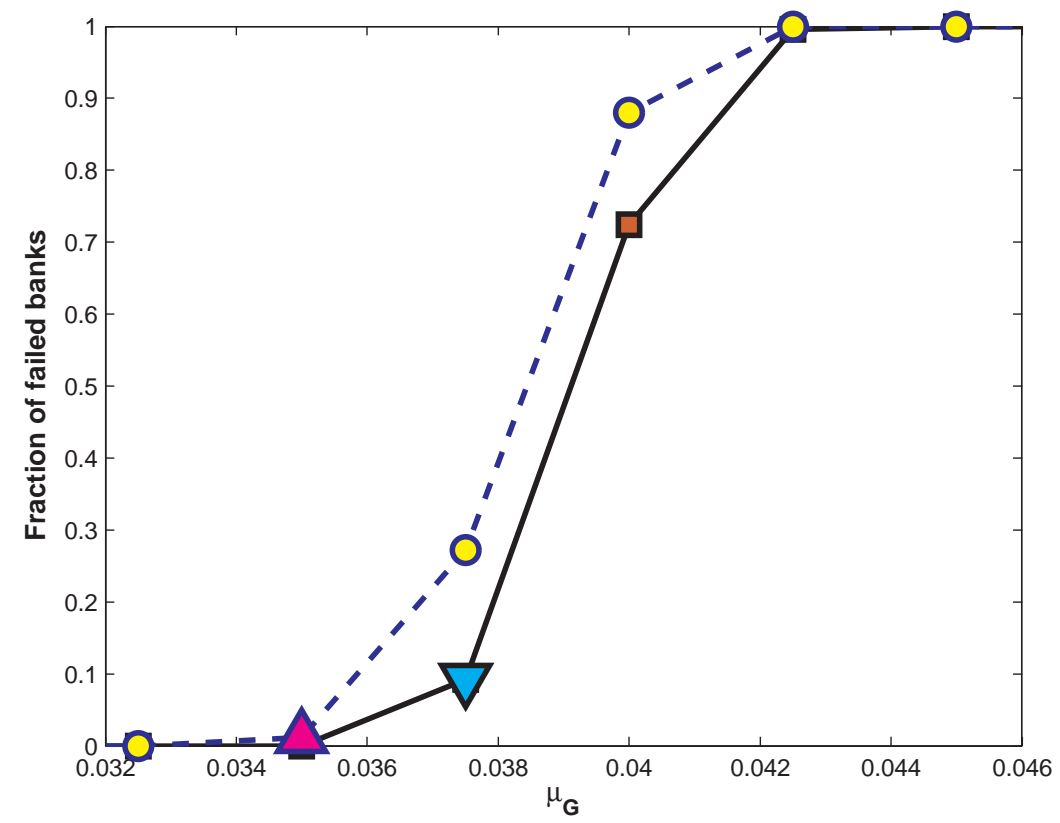

Figure 9: The average fraction of failed banks as a function of $\mu_{G}$. The black line represents the cases where $\lambda=0.7$ and $\psi=0.0$. The downward facing triangle indicates the first instance of total system breakdown. The dashed-blue line is for $\lambda=0.7$ and $\psi=6.25 \times 10^{-5}$. The upward facing triangle indicates the first instance of total breakdown for these parameters. 


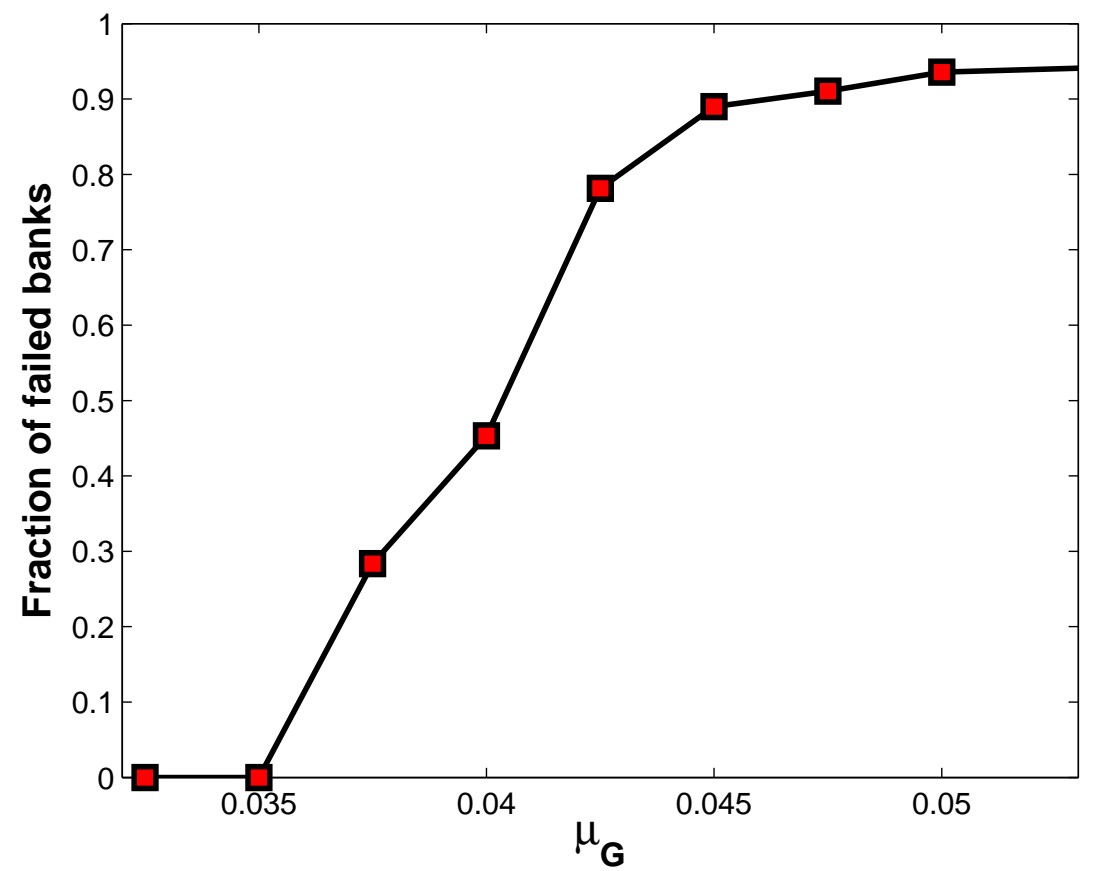

Figure 10: The average fraction of failed banks as a function of $\mu_{G}$, where $\lambda=0.7, \psi=6.25 \times 10^{-5}$ and $\pi$ is random and uniformly distributed in the interval $[0.4,0.24]$. 


\section{SFB 649 Discussion Paper Series 2011}

For a complete list of Discussion Papers published by the SFB 649, please visit http://sfb649. wiwi. hu-berlin.de.

001 "Localising temperature risk" by Wolfgang Karl Härdle, Brenda López Cabrera, Ostap Okhrin and Weining Wang, January 2011.

002 "A Confidence Corridor for Sparse Longitudinal Data Curves" by Shuzhuan Zheng, Lijian Yang and Wolfgang Karl Härdle, January 2011.

003 "Mean Volatility Regressions" by Lu Lin, Feng Li, Lixing Zhu and Wolfgang Karl Härdle, J anuary 2011.

004 "A Confidence Corridor for Expectile Functions" by Esra Akdeniz Duran, Mengmeng Guo and Wolfgang Karl Härdle, January 2011.

005 "Local Quantile Regression" by Wolfgang Karl Härdle, Vladimir Spokoiny and Weining Wang, January 2011.

006 "Sticky Information and Determinacy" by Alexander Meyer-Gohde, January 2011.

007 "Mean-Variance Cointegration and the Expectations Hypothesis" by Till Strohsal and Enzo Weber, February 2011.

008 "Monetary Policy, Trend Inflation and Inflation Persistence" by Fang Yao, February 2011.

009 "Exclusion in the All-Pay Auction: An Experimental Investigation" by Dietmar Fehr and Julia Schmid, February 2011.

010 "Unwillingness to Pay for Privacy: A Field Experiment" by Alastair R. Beresford, Dorothea Kübler and Sören Preibusch, February 2011.

011 "Human Capital Formation on Skill-Specific Labor Markets" by Runli Xie, February 2011.

012 "A strategic mediator who is biased into the same direction as the expert can improve information transmission" by Lydia Mechtenberg and J ohannes Münster, March 2011.

013 "Spatial Risk Premium on Weather Derivatives and Hedging Weather Exposure in Electricity" by Wolfgang Karl Härdle and Maria Osipenko, March 2011.

014 "Difference based Ridge and Liu type Estimators in Semiparametric Regression Models" by Esra Akdeniz Duran, Wolfgang Karl Härdle and Maria Osipenko, March 2011.

015 "Short-Term Herding of Institutional Traders: New Evidence from the German Stock Market" by Stephanie Kremer and Dieter Nautz, March 2011.

016 "Oracally Efficient Two-Step Estimation of Generalized Additive Model" by Rong Liu, Lijian Yang and Wolfgang Karl Härdle, March 2011.

017 "The Law of Attraction: Bilateral Search and Horizontal Heterogeneity" by Dirk Hofmann and Salmai Qari, March 2011.

018 "Can crop yield risk be globally diversified?" by Xiaoliang Liu, Wei Xu and Martin Odening, March 2011.

019 "What Drives the Relationship Between Inflation and Price Dispersion? Market Power vs. Price Rigidity" by Sascha Becker, March 2011.

020 "How Computational Statistics Became the Backbone of Modern Data Science" by James E. Gentle, Wolfgang Härdle and Yuichi Mori, May 2011.

021 "Customer Reactions in Out-of-Stock Situations - Do promotion-induced phantom positions alleviate the similarity substitution hypothesis?" by Jana Luisa Diels and Nicole Wiebach, May 2011.

\section{SFB 649, Spandauer Str. 1, D-10178 Berlin http:/ / sfb649.wiwi.hu-berlin.de}

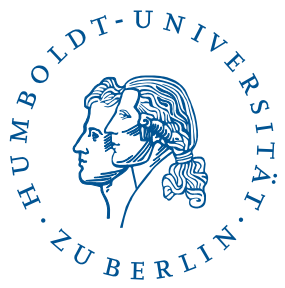




\section{SFB 649 Discussion Paper Series 2011}

For a complete list of Discussion Papers published by the SFB 649, please visit http://sfb649. wiwi. hu-berlin.de.

022 "Extreme value models in a conditional duration intensity framework" by Rodrigo Herrera and Bernhard Schipp, May 2011.

023 "Forecasting Corporate Distress in the Asian and Pacific Region" by Russ Moro, Wolfgang Härdle, Saeideh Aliakbari and Linda Hoffmann, May 2011.

024 "Identifying the Effect of Temporal Work Flexibility on Parental Time with Children" by Juliane Scheffel, May 2011.

025 "How do Unusual Working Schedules Affect Social Life?" by Juliane Scheffel, May 2011.

026 "Compensation of Unusual Working Schedules" by Juliane Scheffel, May 2011.

027 "Estimation of the characteristics of a Lévy process observed at arbitrary frequency" by Johanna Kappus and Markus Reiß, May 2011.

028 "Asymptotic equivalence and sufficiency for volatility estimation under microstructure noise" by Markus Reiß, May 2011.

029 "Pointwise adaptive estimation for quantile regression" by Markus Reiß, Yves Rozenholc and Charles A. Cuenod, May 2011.

030 "Developing web-based tools for the teaching of statistics: Our Wikis and the German Wikipedia" by Sigbert Klinke, May 2011.

031 "What Explains the German Labor Market Miracle in the Great Recession?" by Michael C. Burda and Jennifer Hunt, June 2011.

032 "The information content of central bank interest rate projections: Evidence from New Zealand" by Gunda-Alexandra Detmers and Dieter Nautz, J une 2011.

033 "Asymptotics of Asynchronicity" by Markus Bibinger, J une 2011.

034 "An estimator for the quadratic covariation of asynchronously observed Itô processes with noise: Asymptotic distribution theory" by Markus Bibinger, J une 2011.

035 "The economics of TARGET2 balances" by Ulrich Bindseil and Philipp J ohann König, June 2011.

036 "An Indicator for National Systems of Innovation - Methodology and Application to 17 Industrialized Countries" by Heike Belitz, Marius Clemens, Christian von Hirschhausen, Jens Schmidt-Ehmcke, Axel Werwatz and Petra Zloczysti, June 2011.

037 "Neurobiology of value integration: When value impacts valuation" by Soyoung Q. Park, Thorsten Kahnt, Jörg Rieskamp and Hauke R. Heekeren, June 2011.

038 "The Neural Basis of Following Advice" by Guido Biele, Jörg Rieskamp, Lea K. Krugel and Hauke R. Heekeren, J une 2011.

039 "The Persistence of "Bad" Precedents and the Need for Communication: A Coordination Experiment" by Dietmar Fehr, June 2011.

040 "News-driven Business Cycles in SVARs" by Patrick Bunk, July 2011.

041 "The Basel III framework for liquidity standards and monetary policy implementation" by Ulrich Bindseil and Jeroen Lamoot, J uly 2011.

042 "Pollution permits, Strategic Trading and Dynamic Technology Adoption" by Santiago Moreno-Bromberg and Luca Taschini, July 2011.

043 "CRRA Utility Maximization under Risk Constraints" by Santiago MorenoBromberg, Traian A. Pirvu and Anthony Réveillac, July 2011.

\section{SFB 649, Spandauer Str. 1, D-10178 Berlin http:/ / sfb649.wiwi.hu-berlin.de}

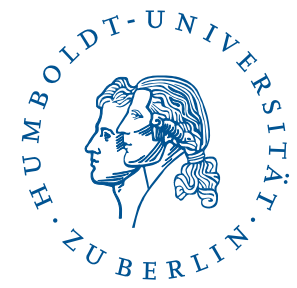




\section{SFB 649 Discussion Paper Series 2011}

For a complete list of Discussion Papers published by the SFB 649, please visit http://sfb649. wiwi. hu-berlin.de.

044 "Predicting Bid-Ask Spreads Using Long Memory Autoregressive Conditional Poisson Models" by Axel Groß-Klußmann and Nikolaus Hautsch, J uly 2011.

045 "Bayesian Networks and Sex-related Homicides" by Stephan Stahlschmidt, Helmut Tausendteufel and Wolfgang K. Härdle, J uly 2011.

046 "The Regulation of I nterdependent Markets", by Raffaele Fiocco and Carlo Scarpa, J uly 2011.

047 "Bargaining and Collusion in a Regulatory Model“, by Raffaele Fiocco and Mario Gilli, July 2011.

048 "Large Vector Auto Regressions", by Song Song and Peter J. Bickel, August 2011.

049 "Monetary Policy, Determinacy, and the Natural Rate Hypothesis", by Alexander Meyer-Gohde, August 2011.

050 "The impact of context and promotion on consumer responses and preferences in out-of-stock situations", by Nicole Wiebach and Jana L. Diels, August 2011.

051 "A Network Model of Financial System Resilience", by Kartik Anand, Prasanna Gai, Sujit Kapadia, Simon Brennan and Matthew Willison, August 2011. 